\title{
Recent Progresses in Oxygen Reduction Reaction Electrocatalysts for Electrochemical Energy Applications
}

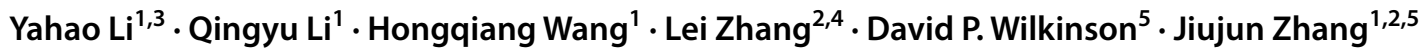

Received: 2 March 2019 / Revised: 29 June 2019 / Accepted: 9 September 2019 / Published online: 1 October 2019

(c) The Author(s) 2019

\begin{abstract}
Electrochemical energy storage systems such as fuel cells and metal-air batteries can be used as clean power sources for electric vehicles. In these systems, one necessary reaction at the cathode is the catalysis of oxygen reduction reaction (ORR), which is the rate-determining factor affecting overall system performance. Therefore, to increase the rate of ORR for enhanced system performances, efficient electrocatalysts are essential. And although ORR electrocatalysts have been intensively explored and developed, significant breakthroughs have yet been achieved in terms of catalytic activity, stability, cost and associated electrochemical system performance. Based on this, this review will comprehensively present the recent progresses of ORR electrocatalysts, including precious metal catalysts, non-precious metal catalysts, single-atom catalysts and metal-free catalysts. In addition, major technical challenges are analyzed and possible future research directions to overcome these challenges are proposed to facilitate further research and development toward practical application.
\end{abstract}

Keywords Oxygen reduction reaction $\cdot$ Electrocatalyst $\cdot$ Precious metal catalyst $\cdot$ Non-precious metal catalyst $\cdot$ Single-atom catalyst $\cdot$ Metal-free catalyst

\section{Introduction}

Fossil fuels, including crude oil, coal and natural gas, as well as nuclear materials are major sources of energy that currently cover the majority of global energy demands [1]. However, fossil fuel reserves are limited and are expected to be depleted within a couple of centuries [1]. In addition,

Qingyu Li

liqingyu62@126.com

1 Guangxi Key Laboratory of Low Carbon Energy Materials, School of Chemical and Pharmaceutical Science, Guangxi Normal University, Guilin 541004, China

2 College of Sciences, Institute for Sustainable Energy, Shanghai University, Shanghai 200444, China

3 State Key Laboratory of Silicon Materials, Key Laboratory of Advanced Materials and Applications for Batteries of Zhejiang Province, and School of Materials Science and Engineering, Zhejiang University, Hangzhou 310027, Zhejiang, China

4 Energy, Mining and Environment, National Research Council Canada, Vancouver, BC V6T 1W5, Canada

5 Department of Chemical and Biochemical Engineering, University of British Columbia, Vancouver, BC V6T 1W5, Canada the combustion of fossil fuels is the main source of greenhouse gases (GHG), especially $\mathrm{CO}_{2}$, which is believed to be the culprit for global warming [2]. And as a major source of demand for energy, transportation currently accounts for $30 \%$ of global energy consumption and $23 \%$ of GHG emission [3, 4]. Based on this, it is of great importance to find green alternatives to combustion engines and reduce GHG emissions. Here, proton exchange membrane (PEM) fuel cells and metal-air batteries stand out among various alternative techniques [5, 6] and are both GHG emission free [5-8]. For PEM fuel cells, hydrogen is used as the fuel and oxygen from air as the oxidant to produce power with only water as the end product whereas for metal-air batteries, metals such as $\mathrm{Li}, \mathrm{Zn}, \mathrm{Mg}$, Al, etc., can be used the fuel electrode and oxygen (air) as the cathode oxidant to produce power. And although different "fuels" are required at the anodes of PEM fuel cells and metal-air batteries, the cathode reaction is always the oxygen reduction reaction (ORR), which in most cases is believed to be the rate-determining step of the overall electrochemical process due to its sluggish kinetics, thus leading to insufficient performances in corresponding devices [9-12]. To overcome this, various cathode electrocatalysts with high activity towards ORR are normally used in which precious metal catalysts, especially 
Pt-based catalysts, are considered to be the most active [13-15]. However, these precious metal catalysts commonly suffer from drawbacks such as high prices and less tolerance to contaminants [16, 17]. Therefore, researchers are devoting great attention to the development of non-precious metal catalysts (NPMC) to replace precious metals in which Fe, $\mathrm{Co}, \mathrm{Ni}, \mathrm{Mg}$ and other metals are being explored to fabricate catalysts with remarkable ORR activity [10, 18-24]. In addition, researchers are also exploring metal-free catalysts that have shown promising ORR activities [16, 17, 25-33]. And based on all of this, this review will present the progresses, challenges and perspectives in the development of ORR electrocatalysts. Furthermore, possible research directions are proposed to facilitate future research and development.

\section{Oxygen Reduction Reaction}

In general, ORR occurs mainly through two pathways in which one is the 4-electron reduction of $\mathrm{O}_{2}$ to $\mathrm{H}_{2} \mathrm{O}$ in acidic media or $\mathrm{OH}^{-}$in basic media whereas the other is the 2-electron reduction of $\mathrm{O}_{2}$ to $\mathrm{H}_{2} \mathrm{O}_{2}$ in acidic media or $\mathrm{HO}_{2}^{-}$in basic media. The thermodynamic reaction potentials for each pathway are listed in Table 1.

As for kinetic ORR sequences, these are more complex and involve many intermediate and elementary steps (electron transfer or chemical reactions) that are dependent on the nature of the catalyst and electrolyte [34] in which in alkaline electrolytes, ORR can occur through associative or dissociative mechanisms [30,35-37]. For the associative mechanism in alkaline media, ORR begins with the associative adsorption of $\mathrm{O}_{2}$ and the overall reaction mechanism can be summarized as follows (*represents a surface free site on the catalyst):

Table 1 ORR pathways on electrodes in aqueous electrolytes [34]

\begin{tabular}{lll}
\hline Electrolyte & Reaction pathway & $\begin{array}{l}\text { Reaction } \\
\text { potential (V vs. } \\
\text { NHE) }\end{array}$ \\
\hline Alkaline electrolyte & $4 \mathrm{e}^{-}$pathway: & \\
& $\mathrm{O}_{2}+2 \mathrm{H}_{2} \mathrm{O}+4 \mathrm{e}^{-} \rightarrow 4 \mathrm{OH}^{-}$ & +0.401 \\
& Peroxide pathway: & \\
& $\mathrm{O}_{2}+\mathrm{H}_{2} \mathrm{O}+2 \mathrm{e}^{-} \rightarrow \mathrm{HO}_{2}^{-}+\mathrm{OH}^{-}-0.065$ \\
& $\mathrm{HO}_{2}^{-}+\mathrm{H}_{2} \mathrm{O}+2 \mathrm{e}^{-} \rightarrow 3 \mathrm{OH}^{-}$ & +0.867 \\
& $\mathrm{Or}$ & Decomposition \\
Acidic electrolyte & $4 \mathrm{e}^{-}$pathway: & \\
& $\mathrm{O}_{2}+4 \mathrm{H}^{+}+4 \mathrm{e}^{-} \rightarrow 2 \mathrm{H}_{2} \mathrm{O}$ & +1.229 \\
& Peroxide pathway: & \\
& $\mathrm{O}_{2}+2 \mathrm{H}^{+}+2 \mathrm{e}^{-} \rightarrow \mathrm{H}_{2} \mathrm{O}_{2}$ & +0.67 \\
& $\mathrm{H}_{2} \mathrm{O}_{2}+2 \mathrm{H}^{+}+2 \mathrm{e}^{-} \rightarrow 2 \mathrm{H}_{2} \mathrm{O}$ & +1.77 \\
& $\mathrm{Or}$ & Decomposition
\end{tabular}

$\mathrm{O}_{2}+{ }^{*}=\mathrm{O}_{2(\mathrm{ads})}$

$\mathrm{O}_{2(\mathrm{ads})}+\mathrm{H}_{2} \mathrm{O}+\mathrm{e}^{-} \rightarrow \mathrm{OOH}_{(\mathrm{ads})}+\mathrm{OH}^{-}$

$\mathrm{OOH}_{(\text {ads })}+\mathrm{e}^{-} \rightarrow \mathrm{O}_{(\mathrm{ads})}+\mathrm{OH}^{-}$

$\mathrm{O}_{(\mathrm{ads})}+\mathrm{H}_{2} \mathrm{O}+\mathrm{e}^{-} \rightarrow \mathrm{OH}_{(\mathrm{ads})}+\mathrm{OH}^{-}$

$\mathrm{OH}_{(\mathrm{ads})}+\mathrm{e}^{-} \rightarrow \mathrm{OH}^{-}+{ }^{*}$

Here, four electrons in total are accepted by $\mathrm{O}_{2}$, resulting in $4 \mathrm{OH}^{-}$ions being produced to complete a 4-electron ORR. Alternatively, if $\mathrm{OOH}_{(\mathrm{ads})}$ accepts an electron, desorption may occur in which peroxide ions are formed and leave the catalytic site, resulting in the termination of the reaction chain and 2 -electron ORR as represented in the following equation:

$\mathrm{OOH}_{(\mathrm{ads})}+\mathrm{e}^{-} \rightarrow \mathrm{OOH}^{-}+*$

As for the dissociative mechanism in alkaline media, this reaction is simpler in which instead of going through Reactions (1) to (3), $\mathrm{O}_{2}$ adsorbed on free sites directly dissociates into two $\mathrm{O}_{(\text {ads }}$, also consuming four electrons and completing a 4-electron ORR as represented in the following equations:

$\frac{1}{2} \mathrm{O}_{2}+* \rightarrow \mathrm{O}_{(\mathrm{ads})}$

$\mathrm{O}_{(\mathrm{ads})}+\mathrm{H}_{2} \mathrm{O}+\mathrm{e}^{-} \rightarrow \mathrm{OH}_{(\mathrm{ads})}+\mathrm{OH}^{-}$

$\mathrm{OH}_{(\mathrm{ads})}+\mathrm{e}^{-} \rightarrow \mathrm{OH}^{-}+{ }^{*}$

As for acidic electrolytes, a similar reaction mechanism occurs in which in the presence of protons, the reaction route will change to:

$\mathrm{O}_{2(\mathrm{ads})}+\mathrm{H}^{+}+\mathrm{e}^{-} \rightarrow \mathrm{OOH}_{(\mathrm{ads})}$

$\mathrm{OOH}_{(\mathrm{ads})}+\mathrm{H}^{+}+\mathrm{e}^{-} \rightarrow \mathrm{O}_{(\text {ads })}+\mathrm{H}_{2} \mathrm{O}$

$\mathrm{O}_{(\mathrm{ads})}+\mathrm{H}^{+}+\mathrm{e}^{-} \rightarrow \mathrm{OH}_{(\mathrm{ads})}$

$\mathrm{OH}_{(\mathrm{ads})}+\mathrm{H}^{+}+\mathrm{e}^{-} \rightarrow \mathrm{H}_{2} \mathrm{O}+{ }^{*}$

Here, four protons and four electrons are consumed and $\mathrm{O}_{2}$ is completely reduced into two $\mathrm{H}_{2} \mathrm{O}$. In addition, Reaction (6) will also change to Reaction $\left(6^{\prime}\right)$ :

$\mathrm{OOH}_{(\mathrm{ads})}+\mathrm{H}^{+}+\mathrm{e}^{-} \rightarrow \mathrm{H}_{2} \mathrm{O}_{2}+*$

And based on these mechanisms, it is clear that the improvement of kinetics and the reduction in overpotentials for ORR in both acidic and alkaline media involve avoiding the production of $\mathrm{H}_{2} \mathrm{O}_{2}$ or $\mathrm{HO}_{2}{ }^{-}$for more efficient 4-electron pathways. And as mentioned above, suitable electrocatalysts can effectively influence reaction mechanisms and guide ORR through more efficient pathways. 


\section{Electrocatalysts for Oxygen Reduction Reactions}

\subsection{Metal catalysts for Oxygen Reduction Reactions}

\subsubsection{Precious Metal Catalysts}

In general, precious metal catalysts, especially Pt-based catalysts, possess high stability and superior electrocatalytic activity in which in many studies, $\mathrm{Pt}$ is often chosen as the reference or baseline catalyst in the exploration of other catalysts such as NPMCs [38]. And although Pt nanoparticles supported by high-surface-area carbon remain the most successfully commercialized ORR electrocatalysts, $\mathrm{Pt}$ is rare and expensive, which limits large-scale application. Overall, the goal of catalyst development, including for Pt and other precious metal-based catalysts, as summarized by Wei et al. [39] is to increase the total number and/or the intrinsic activity of active sites (Fig. 1). To achieve this, researchers have developed many Pt-based catalysts with tunable sizes and morphologies [40-44], including core-shell structured [45-49] and alloy catalysts [50-55]. Here, core-shell structured and alloy catalysts are promising because they can not only reduce $\mathrm{Pt}$ loading by incorporating other metal(s) to allow for higher mass activity $\left(\mathrm{A} \mathrm{mg} \mathrm{Pt}^{-1}\right)$, but can also surpass the intrinsic activity of Pt catalysts through interactions between $\mathrm{Pt}$ and metal counterparts or core metals that can affect electronic structures [43, 56, 57].

Pt Alloy Catalysts Pt alloys with other metals possess superior ORR activities as first discovered three decades ago [58] in which the origin of this higher ORR activity is based on the modification of the electronic structure of $\mathrm{Pt}$, which can affect the adsorption strength of oxygen-containing species on active sites [49, 51, 59-63]. Here, a volcano relationship was demonstrated by Nørskov et al. [64] in which the adsorption energy should be neither too small nor too big to

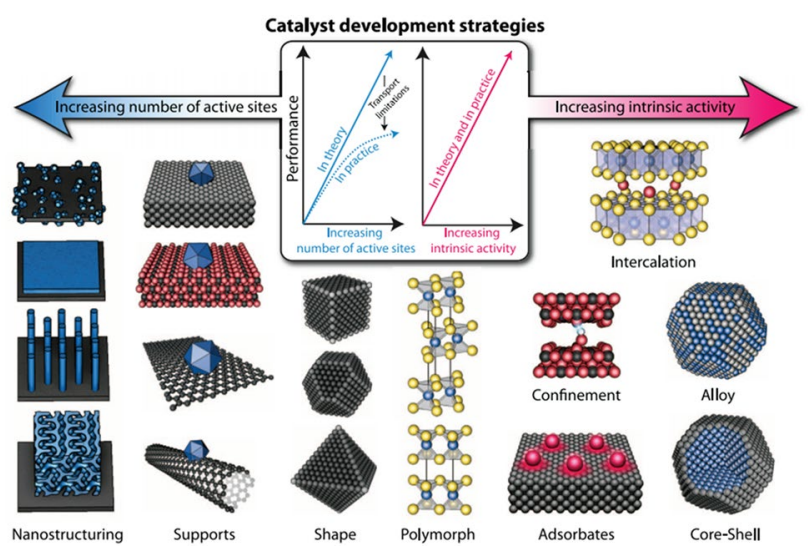

Fig. 1 Different development strategies for metal catalysts. Reprint with permission from [38] balance reactant adsorption ability and resultant desorption ability. Similar relationships have also been established for $\mathrm{Pt}$ alloying with different metals and the tuning of metal ratios (Fig. 2) [50, 53, 65]. In addition, Pt-skin-like surfaces can form during initial treatment and potential cycling to provide more active sites and higher ORR activities to catalysts [58]. Despite these results however, Pt alloyed with transition metals also tends to suffer from leaching or dissolution, which will lead to insufficient stability $[49,56]$ and undermine the advantages of Pt alloy catalysts.

Core-shell Structured Catalysts Pt bimetallic catalysts with core-shell structures are a special type of Pt alloy catalyst in which Pt shells can protect transition metal cores. Here, not only can the dissolution of transition metal cores be mitigated, the interactions between $\mathrm{Pt}$ and core metal(s) are also strong, thus inheriting the advantages of Pt alloy catalysts [48, 56, 57]. In addition, because only small amounts of surface $\mathrm{Pt}$ is utilized during catalytic reactions in these core-shell structures, Pt utilization is maximized, which fulfills the principles of atom economy [66, 67]. For example, Strasser et al. [68] reported that dealloyed $\mathrm{Pt}-\mathrm{Cu}$ core-shell structures can possess extraordinary ORR activity. Here, these researchers reported that strain can form in Pt-enriched shells supported on $\mathrm{Cu}$ cores with a smaller lattice parameter and that the compressive strain in the shell can tune the electronic band structure of Pt and weaken the chemisorption of reactive intermediates, thus resulting in increased ORR activity [37].

Researchers have also observed that Pt alloy catalysts with much higher oxide coverage and faster oxide growth

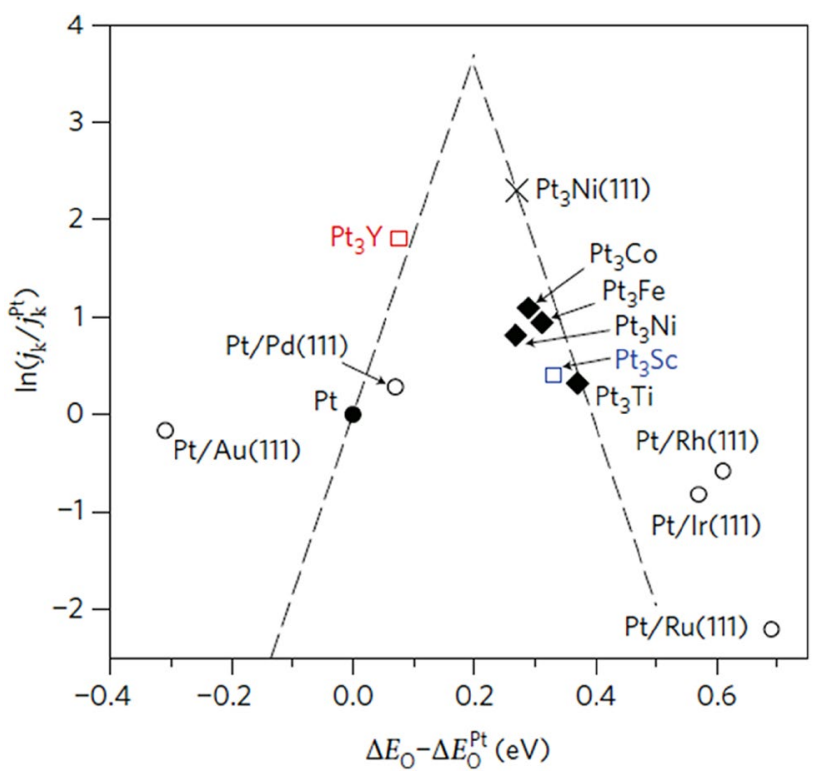

Fig. 2 Volcano plot of ORR kinetic current density $\left(j_{\mathrm{k}}\right)$ as a function of calculated oxygen adsorption energy $\left(\Delta E_{0}\right)$ for Pt alloy electrocatalysts in acidic electrolytes. Reprinted with permission from [65] 
than pure Pt can display excellent ORR activity [69, 70], which conflicts with the conventional knowledge that pure metal surfaces should be more catalytic active than corresponding metal oxide surfaces, indicating that more complex mechanisms are involved for Pt alloy electrocatalysts. Therefore, further investigation into the effects of composition, structure, size and shape of Pt alloys on ORR activity is essential to the design and fabrication of more efficient and economically practical catalysts [38].

\subsubsection{Non-precious Metal Catalysts}

NPMCs have been intensively investigated due to the possibility of eliminating the usage of Pt or other precious metals in which the unique structure of NPMCs (oxides, nitrides, phosphides, etc.) can provide vast possibilities for the tuning of catalyst activity, selectivity, and durability [71, 72].

Transition Metal Oxides Transition metal oxides, including single metal oxides and mixed metal oxides, are representative ORR electrocatalysts that are earth abundant, inexpensive, easy to prepare, environmentally benign and more importantly, possess comparable catalytic activities to Pt-based catalysts.

Transition metals of group VIIB and VIII elements such as $\mathrm{Mn}$ possess multiple valence states and various oxides such as $\mathrm{MnO}, \mathrm{Mn}_{3} \mathrm{O}_{4}, \mathrm{Mn}_{2} \mathrm{O}_{3}$ and $\mathrm{MnO}_{2}$, in which the valence states of $\mathrm{Mn}$ including $\mathrm{Mn}(\mathrm{II}), \mathrm{Mn}$ (III) and $\mathrm{Mn}$ (IV), respectively [38]. Here, the electrocatalyst application of these manganese oxides $\left(\mathrm{MnO}_{x}\right)$ have been intensively investigated after the ORR activity of $\mathrm{MnO}_{2}$ was first reported in the early 1970s [73-78]. As a result, the chemical composition, texture, morphology, oxidation state and crystalline structure of $\mathrm{MnO}_{x}$ have been examined in electrocatalytic applications. For example, the crystallographic structures of $\mathrm{MnO}_{2}$ were reported to possess catalytic activities in alkaline electrolytes following the order: $\alpha-\mathrm{MnO}_{2}>$ amorphous $\mathrm{MnO}_{2}>\beta-\mathrm{MnO}_{2}>\gamma-\mathrm{MnO}_{2}[79,80]$ in which these activities were believed to be related to their intrinsic tunnel size and electrical conductivity. Delmondo et al. [81] also reported the thermal evolution of $\mathrm{Mn}_{x} \mathrm{O}_{y}$ nanofibers with changed ORR activity in which at a lower temperature zone $\left(475-575^{\circ} \mathrm{C}\right), \mathrm{Mn}_{x} \mathrm{O}_{y}$ existed as a single phase of $\mathrm{Mn}_{3} \mathrm{O}_{4}$ whereas a single phase of $\mathrm{Mn}_{2} \mathrm{O}_{3}$ was found at a higher temperature zone (above $725^{\circ} \mathrm{C}$ ). And although both phases exhibited good ORR activity, the mixture of these two phases at temperatures between 575 and $625^{\circ} \mathrm{C}$ provided poor activity and selectivity. Researchers have also reported that $\mathrm{Mn}{ }^{\mathrm{III}} / \mathrm{Mn}^{\mathrm{IV}}$ species were the intermediates during ORR and that the doping of low-valent metal elements into $\mathrm{MnO}_{x}$ can enhance overall ORR activity due to the ability of these elements to stabilize $\mathrm{Mn}^{\mathrm{III}} / \mathrm{Mn}^{\mathrm{IV}}$ species [82]. Alternatively, Risch et al. [83] also studied the redox process of $\mathrm{MnO}_{x}$ during ORR using in situ soft X-ray absorption spectroscopy and reported that $\mathrm{Mn}^{\mathrm{III} /} \mathrm{Mn}^{\mathrm{II}}$ instead of $\mathrm{Mn}^{\mathrm{III}} / \mathrm{Mn}^{\mathrm{IV}}$ species were the species relevant to ORR and that the $\mathrm{Mn}^{\mathrm{III}} / \mathrm{Mn}^{\mathrm{IV}}$ pair was believed to be more related the oxygen evolution reaction (OER). Furthermore, researchers have also reported that aside from valance status, the micro-morphology of manganese oxides can also affect electrocatalytic activity in which suitable morphologies such as nanorods [84, 85], nanowires [86, 87] and nanospheres [88] can profoundly enhance ORR activity.

Cobalt oxides also possess high electrocatalytic activities and tunable compositions and are another type of promising candidates to catalyze ORR [73]. The most commonly investigated cobalt oxide is $\mathrm{Co}_{3} \mathrm{O}_{4}$ in which $\mathrm{Co}^{2+}$ and $\mathrm{Co}^{3+}$ ions coexist in the crystal structure. And although the exact catalytic mechanism for $\mathrm{Co}_{3} \mathrm{O}_{4}$ active sites remains unclear, different assumptions have been made. For example, $\mathrm{Xu}$ et al. [89] reported that $\mathrm{Co}_{3} \mathrm{O}_{4}$ nanorods with more exposed surface $\mathrm{Co}^{3+}$ ions can lead to higher catalytic ORR activities that can surpass the activity of $\mathrm{Pd}$ catalysts, suggesting that surface $\mathrm{Co}^{3+}$ ions on $\mathrm{Co}_{3} \mathrm{O}_{4}$ electrocatalysts play a determinant role in ORR performance. Alternatively, $\mathrm{He}$ et al. [90] believed that increased ORR activity is associated with higher amounts of $\mathrm{Co}^{2+}$ whereas higher amounts of $\mathrm{Co}^{3+}$ will lead to better OER activity in which these researchers suggested that $\mathrm{Co}^{3+}$ active sites can enhance the adsorption of $\mathrm{OH}^{-}$anions, which can act as reactants for OER. These researchers also suggested that more $\mathrm{Co}^{2+}$ active sites can aid in the adsorption of $\mathrm{O}_{2}$ and subsequent electron transfer to generate $\mathrm{OH}^{-}$through ORR. Osgood et al. [91] also suggested that the increased availability and faster frequency of these reactants occurring at active sites due to the respective Co oxidation states can enhance reaction rates. And because ORR is a surface-structure-sensitive reaction and Co cations can play an essential role, the tailoring of $\mathrm{Co}_{3} \mathrm{O}_{4}$ morphologies to provide more active sites is an effective strategy to enhance ORR activity.

Intrinsically, single metal oxides possess poor electric conductivity; therefore, supporting them on conductive substrates such as carbon materials is necessary to enhance catalytic performance [80, 92-94]. Moreover, the interaction between metal oxides and substrates can affect ORR activity [92, 93, 95, 96]. For example, Savinova et al. [92] reported that in addition to being a conductive support to enhance the conductivity of $\mathrm{MnO}_{x}$ and providing additional active sites, carbon support materials can actually compete with oxides during $\mathrm{O}_{2}$ adsorption. And based on this observation, these researchers suggested that carbon materials with high surface areas should be avoided to relieve this competition. Alternatively, Tong et al. [93] coupled $\mathrm{CoO}_{x}$ to $\mathrm{B}, \mathrm{N}$ decorated graphene $\left(\mathrm{CoO}_{x} / \mathrm{BNG}\right)$ and reported that $\mathrm{Co}-\mathrm{N}-\mathrm{C}$ species formed and acted as a bridge between $\mathrm{CoO}_{x}$ nanoparticles and BNG, resulting in excellent ORR activities, 
which these researchers ascribed to the interactions between $\mathrm{CoO}_{x}$ and $\mathrm{BNG}$.

Mixed-metal (bi-metal, tri-metal or more) oxides have also been extensively investigated to catalyze ORR because they naturally possess metals with different valence states. And of these mixed-metal oxides, spinel-type and perovskite-type oxides are the most investigated [73].

(a) Spinel-type oxides [97-102]: Spinel-type oxides are a group of oxides with the formula: $\mathrm{A}^{2+} \mathrm{B}_{2}^{3+} \mathrm{O}_{4}{ }^{2-}$, in which $\mathrm{A}$ is a divalent metal ion $\left(\mathrm{Mg}^{2+}, \mathrm{Fe}^{2+}, \mathrm{Mn}^{2+}, \mathrm{Ni}^{2+}\right.$, etc. $)$ and $\mathrm{B}$ is a trivalent metal ion $\left(\mathrm{Al}^{3+}, \mathrm{Fe}^{3+}, \mathrm{Co}^{3+}, \mathrm{Cr}^{3+}\right.$, etc.). Typical spinel structures (Fig. 3a) are usually cubic close-packed oxides with two tetrahedral and four octahedral sites per formula unit in which if $\mathrm{B}^{3+}$ ions occupy octahedral holes and $\mathrm{A}^{2+}$ ions occupy tetrahedral holes; the structure is called a "normal spinel." Alternatively, if $\mathrm{B}^{3+}$ ions occupy tetrahedral holes and half of the octahedral holes and $\mathrm{A}^{2+}$ ions occupy the rest of the octahedral holes, the structure is called an "inverse spinel." And in some occasions, these two types of structures can coexist in one material with the corresponding structure called a "mixed spinel" [103]. Spinel oxides can exhibit good ORR activity in alkaline electrolytes [97-102, 104] and Mn and Co are the two most investigated metal species because both possess multiple valence states and can provide various possibilities [23, 75, 101, 102, 105]. For example, Zhou et al. [102] explored the effects of Mn-Co compositional change on ORR activity by studying the catalytic properties of a series of edge sharing $\left[\mathrm{Co}_{x} \mathrm{Mn}_{1-x} \mathrm{O}_{6}\right]$ octahedra units and reported that the ORR activity of spinels mainly originate from octahedral units. Here, these researchers proposed that the super-exchange interaction ( $\mathrm{Mn}-\mathrm{O}-\mathrm{Co}$ ) between mixed $\left[\mathrm{MnO}_{6}\right]-\left[\mathrm{CoO}_{6}\right]$ octahedra through the oxygen "edge" in spinel lattices can dominate the electronic behavior of octahedral metal cations.

Overall, spinel oxides are normally conductors or semiconductors due to their mixed valence states in which electronic transfer can occur with relatively low activation energies between the cations of different valence states through hopping, allowing spinel oxides to not only be used as catalysts but also as electrode materials [73], which can resolve issues faced by single metal oxides.

(b) Perovskite-type oxides: Perovskites are oxides with a general formula of $\mathrm{ABO}_{3}$ and have been extensively investigated due to their bifunctional catalytic ability in alkaline electrolytes [73, 107-110]. The basic structure of perovskite-type oxides involves an orthorhombic structure with A-site cations being coordinated to 12 oxygen ions to form a cuboctahedral coordination environment and B-site cations being coordinated to six oxygen ions to form an octahedral geometry (Fig. 3b) [106], allowing for high stability at high temperatures. In addition, $~ 90 \%$ of natural metallic elements are known to be stable in a perovskitetype oxide structure [108] in which perovskites can be partially substituted to form materials with the formula $\mathrm{A}_{1-x} \mathrm{~A}_{x}{ }^{\prime} \mathrm{B}_{1-y} \mathrm{~B}_{y}{ }^{\prime} \mathrm{O}_{3}$. The properties of these perovskites can also largely differ from origin oxides, and therefore, the structural variation of perovskite-type oxides makes them promising for catalytic applications.

La-based perovskite oxides with La ions located in A-sites have been extensively investigated and applied in various applications [111-116], particularly in the catalysis of ORR [109, 110, 116]. For example, Sunarso et al. [109] investigated the ORR activities of La-based perovskite oxides in alkaline media and reported that the increasing order of ORR activity for La-based perovskite oxides with different transition metal ions in B-sites was: $\mathrm{LaCrO}_{3}<\mathrm{LaFeO}_{3}<\mathrm{LaNiO}_{3}<\mathrm{LaMnO}_{3}<\mathrm{LaCoO}_{3}$. In addition, these researchers also reported that if half of the B-site metals were replaced with $\mathrm{Ni}$, the order of ORR activity changes to: $\mathrm{LaNiO}_{3}<\mathrm{LaNi}_{0.5} \mathrm{Fe}_{0.5} \mathrm{O}_{3}<\mathrm{La}$ $\mathrm{Ni}_{0.5} \mathrm{Co}_{0.5} \mathrm{O}_{3}<\mathrm{LaNi}_{0.5} \mathrm{Cr}_{0.5} \mathrm{O}_{3}<\mathrm{LaNi}_{0.5} \mathrm{Mn}_{0.5} \mathrm{O}_{3}$ and that the ORR onset potentials of the substituted oxides were improved, suggesting the beneficial effects of substation by two transition metal cations.

Transition Metal Nitrides The significant electronegativity difference between metals and $\mathrm{N}$ can allow for charge delocalization in nitrides, which can create basic or acidic sites with good catalytic activity towards isomerization,
Fig. 3 a Typical spinel crystal structure. b Structure of perovskite-type oxide emphasizing the coordination number of the A cation at the body center. Reprinted with permission from $[97,106]$
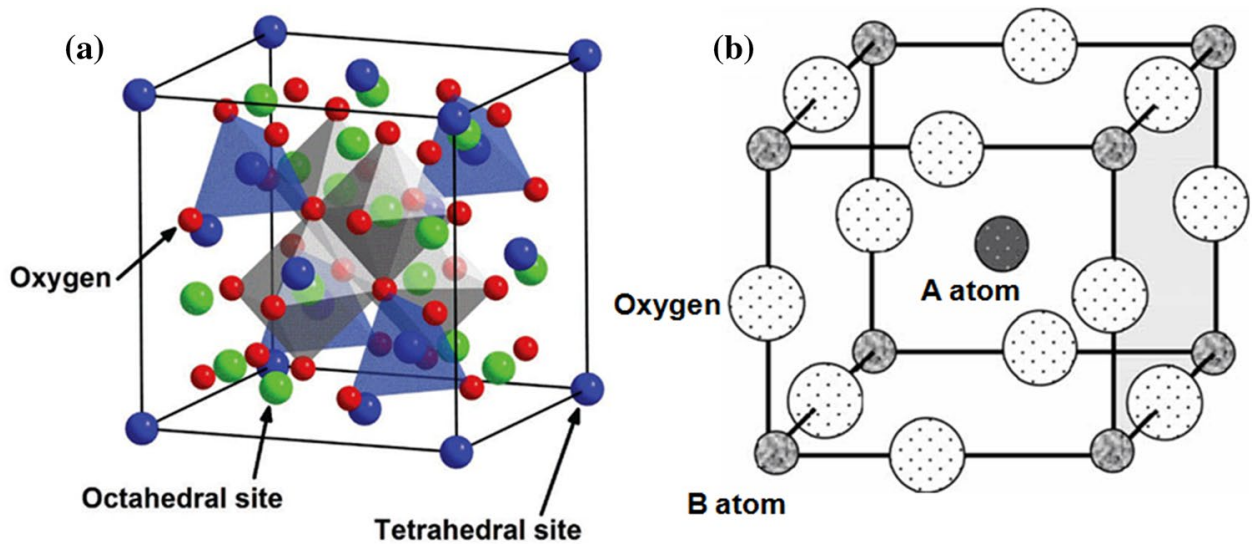
dehydrogenation, hydrogenation, etc. [73]. The first nitride to be used to catalyze ORR in 1963 was TiN, which was found to possess good ORR activity and excellent electronic conductivity in alkaline electrolytes [117]. Because of this, transition metal nitride catalysts have been intensively explored for ORR catalysis. For example, $\mathrm{Mn}_{4} \mathrm{~N}$ was found to possess high ORR activity in alkaline electrolytes and provide a direct 4-electron ORR mechanism [118]. In addition, molybdenum nitrides have also been investigated as ORR electrocatalysts [119-121]. Overall, the research into metal nitrides focuses more on $\mathrm{N}$-doped carbon-supported metal nitride composites, not only because these $\mathrm{N}$-doped carbon materials can provide extra ORR activity through the synergistic effects between supports and nitrides, but also because of the possible formation of metal- $\mathrm{N}_{x}$ moieties during synthesis, which can show high catalytic activity towards ORR [122-126].

As for metal- $\mathrm{N}_{x}$ moieties, metal and $\mathrm{N}$ can both contribute to catalytic activity; however, it is difficult to determine individual contribution. To address this, Wang et al. [127] recently reported the successful exclusion of $\mathrm{Fe}-\mathrm{N}_{x}$ moieties in $\mathrm{Fe}-\mathrm{N}-\mathrm{C}$ systems $\left(\mathrm{Fe}_{2} \mathrm{~N}\right.$ and $\mathrm{N}$-doped graphene $)$ in which these researchers used DFT calculations to determine that $\varepsilon-\mathrm{Fe}_{x} \mathrm{~N}(x \leqslant 2.1)$ was more active than $\zeta-\mathrm{Fe}_{2} \mathrm{~N}$ in the catalysis of ORR.

Researchers have also reported that $\mathrm{Cu}_{3} \mathrm{~N}$ can be prepared through a one-phase process in which the crystal size of the product can be easily tuned using different primary amines as capping agents. Here, the resulting nanocrystal structures can lead to improved ORR activities in alkaline fuel cells [128] and this enhanced activity can be partially attributed to the nanostructure. This is because nanostructured materials possess additional advantages for electrocatalysis due to the favorable access of electrolytes to reactive sites, thus promoting the mass transfer of reactant gases and ions conducting in the catalyst layer [73, 129, 130]. For example, Chen et al. [131] demonstrated that TiN nanoparticles can be directly synthesized on carbon black supports using an $\mathrm{mpg}-\mathrm{C}_{3} \mathrm{~N}_{4}$-carbon black composite as a template and resulted in strong contact between the TiN and carbon support in the resulting catalyst and high ORR activity in a corresponding acidic fuel cell.

Transition Metal Phosphides Recently, the electrocatalytic performance of transition metal phosphides (TMPs) have also been explored [132-134]. Although TMPs such as iron phosphide [135], nickel phosphide [136], cobalt phosphide [137] and others [138-145] have been reported to possess catalytic activities toward hydrogen evolution reaction (HER), they have rarely been employed as ORR catalysts. However, researchers such as Yang et al. [146] reported that urchin-like CoP nanocrystals can possess both HER and ORR activities in acidic media. Doan-Nguyen et al. [147] also prepared $\mathrm{Co}_{2} \mathrm{P}$ nanorods through the thermal decomposition of metal salt precursors and reported uniform crystals with ORR activity and stability in alkaline electrolytes. In addition, TMPs have also been composited with other materials such as carbon materials to achieve better performances. For example, Chen et al. [148] synthesized $\mathrm{M}_{2} \mathrm{P}(\mathrm{M}=\mathrm{Co}, \mathrm{Mn}, \mathrm{Ni}) /$ heteroatom-doped carbon nanotube composites and reported that all of their $\mathrm{M}_{2} \mathrm{P}$ were successfully synthesized and exhibited ORR activities in the order of: $\mathrm{Mn}_{2} \mathrm{P}>\mathrm{Co}_{2} \mathrm{P}>\mathrm{Ni}_{2} \mathrm{P}$ in alkaline media.

ORR activity catalyzed by TMPs was also reported by Zhang et al. [149]. Here, FeP embedded in N, P dual-doped porous carbon nanosheets was synthesized through the pyrolysis of precursor powders consisting of iron phytate and folic acid (Fig. 4a) with the resulting TEM images (Fig. 4b) showing 18-40 nm carbon nanosheet confined FeP nanoparticles. And in subsequent electrochemical evaluations (Fig. 4c), it was found that the onset potential of FeP@ NPCs was comparable to that of $\mathrm{Pt} / \mathrm{C}$ and that the half-wave potential was $\sim 15 \mathrm{mV}$ more positive than $\mathrm{Pt} / \mathrm{C}$. Here, these superb performances were ascribed to the enhancement of charge delocalization and the asymmetric spin density of carbon atoms due to the doping of $\mathrm{P}$ and the good electric conductivity and high intrinsic ORR activity of the TMPs.

\subsection{Single-Atom Catalysts}

The concept of single-atom catalysts (SACs) was first proposed by Qiao et al. [150] in 2011 and has been extended to many catalytic areas and is a fast-growing area of research [36, 151-153]. In SACs, each metal atom can act as one catalytic active site or center in which the interaction between single atoms and supports can lead to promising properties [154].

\subsubsection{Precious Metal Single-Atom Catalysts}

Precious metals can provide excellent ORR activities but are cost prohibitive. Therefore, the synthesis of precious metal SACs is an effective method to maximize utilization and reduce costs. In addition, the uniformity of the surrounding environment of centered metal atoms can allow for better rational designs and modeling for mechanism studies [44, 155-159]. However, actual ORR activities in these precious metal SACS are not ideal in which most reported precious metal SACs provided ORR activities that were barely comparable to that of $\mathrm{Pt}$ nanoparticles $(\mathrm{Pt} / \mathrm{C})$ [44, 155, 157-159]. Furthermore, facets on precious metal nanoparticles such as $\operatorname{Pt}(111)$ appeared to be actually more active than precious metal single atoms. For more information concerning precious metal SACs, a recent review has recently been published [160]. 
Fig. 4 a Schematic of the formation process of $\mathrm{FeP}$ embedded in N, P-dual doped 2D porous carbon nanosheets (FeP@NPCs). b TEM image of the FeP@NPC. c Comparison of rotating disk electrode (RDE) polarization curves of different catalysts in $\mathrm{O}_{2}$-saturated $0.1 \mathrm{M} \mathrm{KOH}$ with a scan rate of $5 \mathrm{mV} \mathrm{s}^{-1}$ and a rotation speed of $1600 \mathrm{rpm}$. Reprinted with permission from [149]

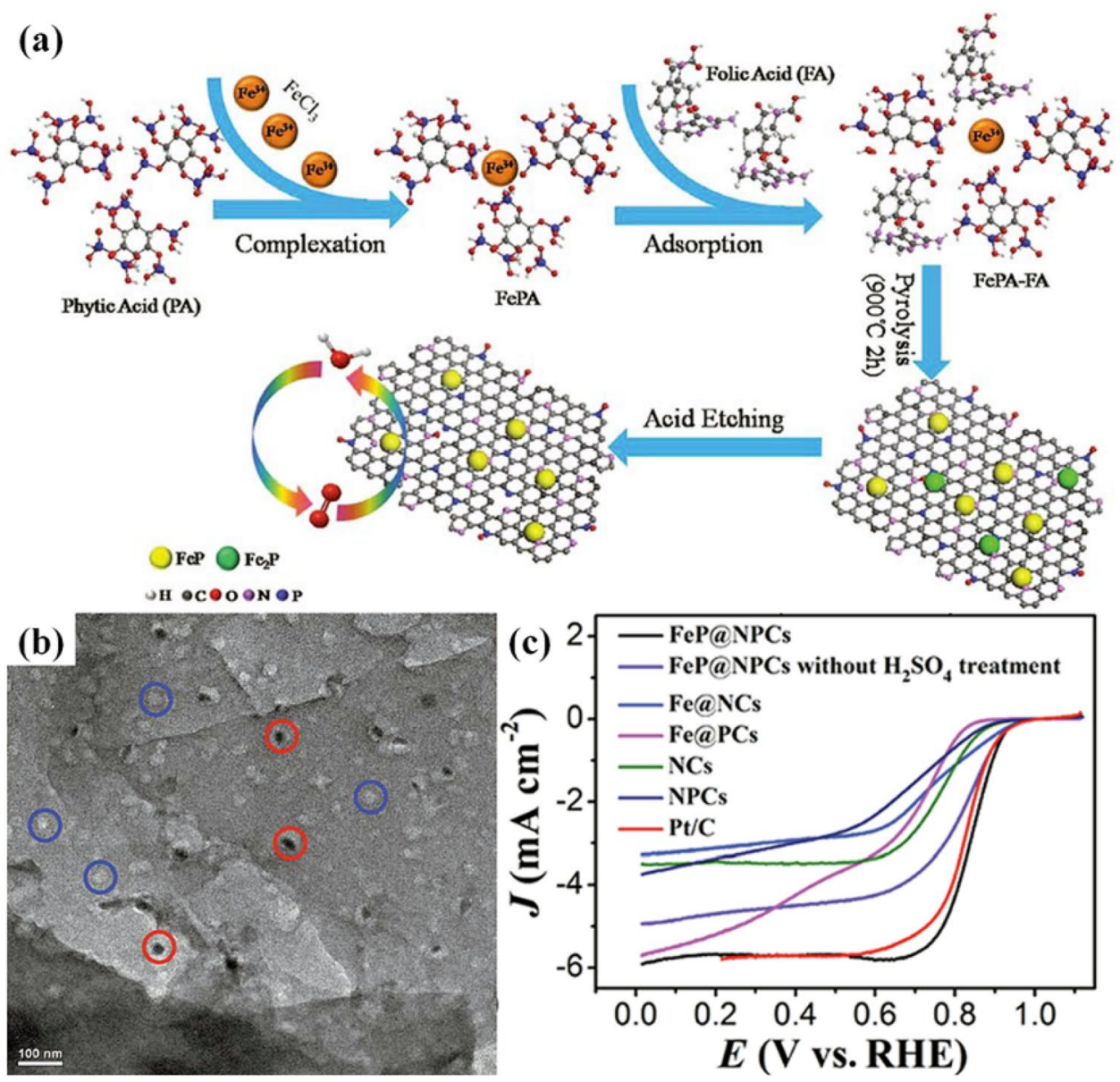

\subsubsection{Non-precious Metal Single Atom Catalysts}

The use of inexpensive transition metals to replace precious metals can reduce costs and facilitate large-scale application. Because of this, this has become a trend in the design and fabrication of ORR catalysts, including non-precious metal SACs.

Metal-nitrogen Complex Transition metal-nitrogen complex materials $\left(\mathrm{M}-\mathrm{N}_{x} / \mathrm{C}, \mathrm{M}=\mathrm{Co}, \mathrm{Fe}, \mathrm{Ni}, \mathrm{Mn}\right.$, etc. and normally $x=2$ or 4) with limited metal and inexpensive carbon supports have showed promising ORR activities [10, 20, 21, $24,129,161]$ and based on synthesis processes, $\mathrm{M}-\mathrm{N}_{x} / \mathrm{C}$ catalysts can be classified into non-pyrolyzed catalysts with organic states and pyrolyzed catalysts with inorganic states. Here, non-pyrolyzed $\mathrm{M}-\mathrm{N}_{x} / \mathrm{C}$ catalysts can maintain welldefined structures of macrocycle complexes during simple synthesis procedures and can provide favorable structural control for their activity. Alternatively, pyrolyzed $\mathrm{M}-\mathrm{N}_{x} / \mathrm{C}$ catalysts are normally obtained through heat-treating non-pyrolyzed $\mathrm{M}-\mathrm{N}_{x} / \mathrm{C}$ and can result in superb catalytic activities.

(a) Non-pyrolyzed $M-N_{x} / C$ materials Transition metal macrocycle compounds have been employed in many catalysis applications for various processes over the decades $[129,162]$. And after $\mathrm{M}-\mathrm{N}_{x} / \mathrm{C}$ materials (cobalt phthalocyanines, CoPc, metal- $\mathrm{N}_{4}$ chelates) were reported to be able to catalyze ORR in $25 \% \mathrm{KOH}$ electrolyte [163], transition metal porphyrins such as tetraphenyl porphyrin, tetramethoxy tetraphenyl porphyrin and phthalocyanine $(\mathrm{Pc})$ have been thoroughly studied in the development of novel ORR electrocatalysts [73, 129, 164-167]. Although the results of these studies have not been ideal because the activity and stability of these non-pyrolyzed $\mathrm{M}-\mathrm{N}_{x} / \mathrm{C}$ catalysts were insufficient for energy storage systems [129], they can act as example systems for fundamental research because their well-defined structures can allow researchers to easily correlate catalyst structural features to exhibited ORR activities and stabilities in which the ORR activity catalyzed by these well-defined structured catalysts has been found to be directly related to the metal ion centers coordinated by ligands [168]. Here, corresponding ORR activity in alkaline electrolytes can be plotted using a volcano correlation based on various reports and through comparisons of DFTcalculated $\mathrm{O}_{2}$ binding energies on the metal centers of different M- $\mathrm{N}_{x} / \mathrm{C}$ catalysts (Fig. 5a) [169] in which researchers have suggested that binding energies should be neither 

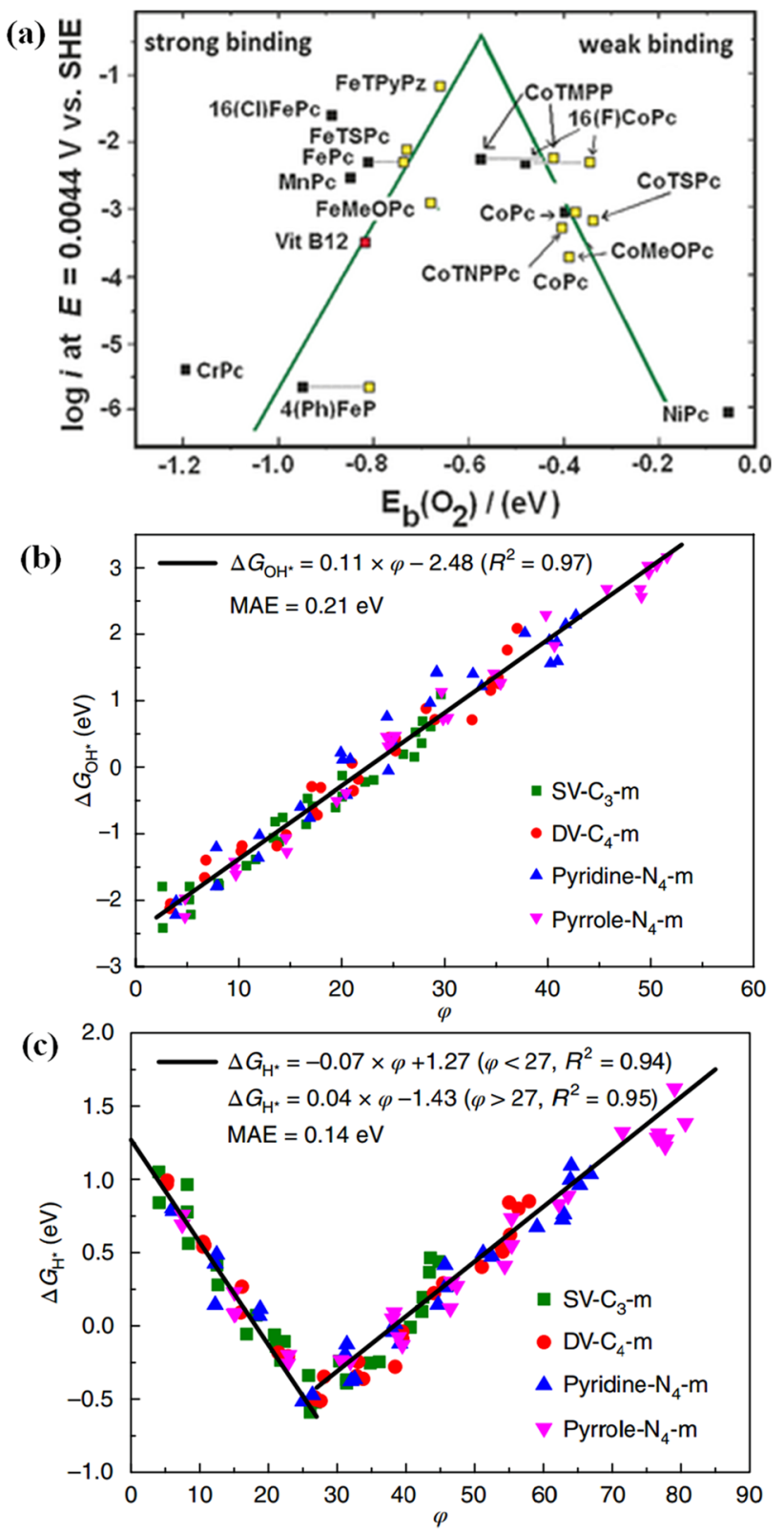

Fig. 5 a Activity volcano correlation for the reduction of $\mathrm{O}_{2}$ in $0.1 \mathrm{~m}$ $\mathrm{NaOH}$ on different molecular $\mathrm{MN}_{4}$ catalysts adsorbed on ordinary pyrolytic graphite. Reprinted with permission from [169]. b Scatter of adsorption free energy of $\mathrm{OH}$ versus the descriptor $\varphi$ for all single transition metal atoms supported on macrocyclic molecules. c Scatter of adsorption free energy of $\mathrm{H}$ versus the descriptor $\varphi$ for all single transition metal atoms supported on macrocyclic molecules. The black line represents the function obtained from single transition metal atoms supported on graphene. Mean absolute differences (MAE) between predicted values based on the black line and calculated values are given. Reprinted with permission from [170]

too weak to facilitate the adsorption of $\mathrm{O}_{2}$ nor too strong to allow for the release of intermediates such as $\mathrm{H}_{2} \mathrm{O}_{2}$ for subseqent reaction steps. Moreover, an interesting phenomenon was also reported in which the two sides of the volcano plot can separate 4-electron pathway catalysts from 2-electron pathway catalysts. Recently, Xu et al. [170] took one step further and proposed a universal descriptor $\varphi$ to correlate the $\Delta G_{\mathrm{OH}^{*}}$ of most transition metal single atoms supported on graphene and reached the conclusion that the catalytic activity of SACs was highly correlated with the coordination number and electronegativity of the metal center as well as the electronegativity of the nearest neighboring atom. These researchers subsequently proved their theory using experimental data and further extended $\varphi$ to single transition metal atoms supported on macrocyclic molecules (Fig. 5b, c), resulting in the finding that $\mathrm{Fe}$-pyridine/pyrrole- $\mathrm{N}_{4}$ materials were the most suitable SACs for ORR. And overall, the results in this study can provide good rational design principles for future SAC research.

(b) Pyrolyzed $M-N_{x} / C$ materials Non-pyrolyzed $\mathrm{M}-\mathrm{N}_{x} / \mathrm{C}$ materials suffer from poor stability and low ORR activity. A significant breakthrough was made however in which the high-temperature $\left(400\right.$ to $\left.1000{ }^{\circ} \mathrm{C}\right)$ treatment of nonpyrolyzed $\mathrm{M}-\mathrm{N}_{x} / \mathrm{C}$ materials was introduced to catalyst synthesis, leading to significant enhancements in both catalytic activity and stability $[73,129,171-173]$. And with progress in the synthesis methods of pyrolyzed $\mathrm{M}-\mathrm{N}_{x} / \mathrm{C}$ materials, researchers have found that macrocycle compounds were not necessarily the only precursor choice and that the simple pyrolysis of transition metal, carbon and nitrogen containing precursors can also produce catalytically active $\mathrm{M}-\mathrm{N}_{x} / \mathrm{C}$ catalysts for ORR, providing tremendous possibilities for the development of efficient non-noble metal catalysts. To further enhance the ORR activity and stability of pyrolyzed $\mathrm{M}-\mathrm{N}_{x} / \mathrm{C}$ catalysts, research has also been dedicated to the optimization of other important factors, including transition metal type and loading, carbon supports, nitrogen content and heat treatment conditions and duration [168]. Several transition metals including $\mathrm{Fe}, \mathrm{Co}, \mathrm{Mn}, \mathrm{Ni}, \mathrm{Cu}$ and $\mathrm{Cr}$ have also been investigated as active centers for $\mathrm{M}-\mathrm{N}_{x} / \mathrm{C}$ catalysts, and many researchers have suggested that $\mathrm{Fe}$ and $\mathrm{Co}$ are the most active transition metal ion centers for ORR catalysis $[72,129,168]$. In addition, researchers have also reported that the ORR activity of $\mathrm{M}-\mathrm{N}_{x} / \mathrm{C}$ catalysts can be significantly enhanced if one catalyst contained two or more different types of metal ion centers in which in the synthesis of pyrolyzed $\mathrm{M}-\mathrm{N}_{x} / \mathrm{C}$ catalysts, metal precursors were either inorganic metal salts or organometallic complexes. Furthermore, the introduction of $\mathrm{N}$ onto catalyst surfaces is considered to be the most critical step in determining catalyst performance [73]. Here, $\mathrm{N}$ precursors include gaseous materials such as $\mathrm{NH}_{3}$ or $\mathrm{CH}_{3} \mathrm{CN}$ [174], organic small molecules such as pyrrole [175], phenanthroline [24] or ethylenediamine [176] and N-containing polymers such as polyaniline [177]. As for carbon supports, researchers have reported that disordered carbon degree and micro-porosity were both influential factors [178, 179]. And therefore, the development 
of highly efficient $\mathrm{M}-\mathrm{N}_{x} / \mathrm{C}$ catalysts requires holistic optimizations. For example, Lefèvre et al. [24] synthesized a Fe-based catalyst with ORR catalytic activities comparable to Pt in a polymer electrolyte fuel cell and reported that optimal site densities can be achieved by mixing and pyrolyzing precursors in a specific procedure involving two-phase heat treatment under different atmospheres.

Active sites are important for oxygen electrocatalysts; however, the actual configuration of these active sites remains unclear, especially in the case of pyrolyzed $\mathrm{M}-\mathrm{N}_{x} / \mathrm{C}$ catalysts [73]. And although many results have suggested that transition metal ions coordinated by pyridinic $\mathrm{N}$ function groups are the active sites, many alternative coordination structures for active sites have been proposed as well, including edge plane $\mathrm{M}-\mathrm{N}_{2} / \mathrm{C}$ and $\mathrm{M}-\mathrm{N}_{4} / \mathrm{C}$ species, basal plane macrocyclic $\mathrm{M}-\mathrm{N}_{4} / \mathrm{C}$ species and graphitic nitrogen $\mathrm{N} / \mathrm{C}$ species. However, none of these can provide enough evidence to clarify the overall picture [168]. Furthermore, Jia et al. [180] recently proposed three types of $\mathrm{Fe}-\mathrm{N}_{4} / \mathrm{C}$ active centers (Fig. 6) and suggested that different $\mathrm{Fe}-\mathrm{N}_{4}$ switching behaviors during ORR in acidic media existed and are controlled by the dynamic structure associated with $\mathrm{Fe}^{\mathrm{III}} / \mathrm{Fe}^{\mathrm{II}}$ redox transition [169] in which the higher catalytic activity of pyrolyzed $\mathrm{Fe}-\mathrm{N}_{4} / \mathrm{C}$ may be associated with the more electron-withdrawing environment around the $\mathrm{Fe}-\mathrm{N}$ coordination structure as induced by pyrolysis, leading to a positive shift in the $\mathrm{Fe} \mathrm{E}^{\mathrm{III}} / \mathrm{Fe}^{\mathrm{II}}$ redox potential for ORR.

Other Single Atom Catalysts The ORR activity of SACs is highly dependent on the properties of metal centers and their surrounding environments. In addition, the binding of

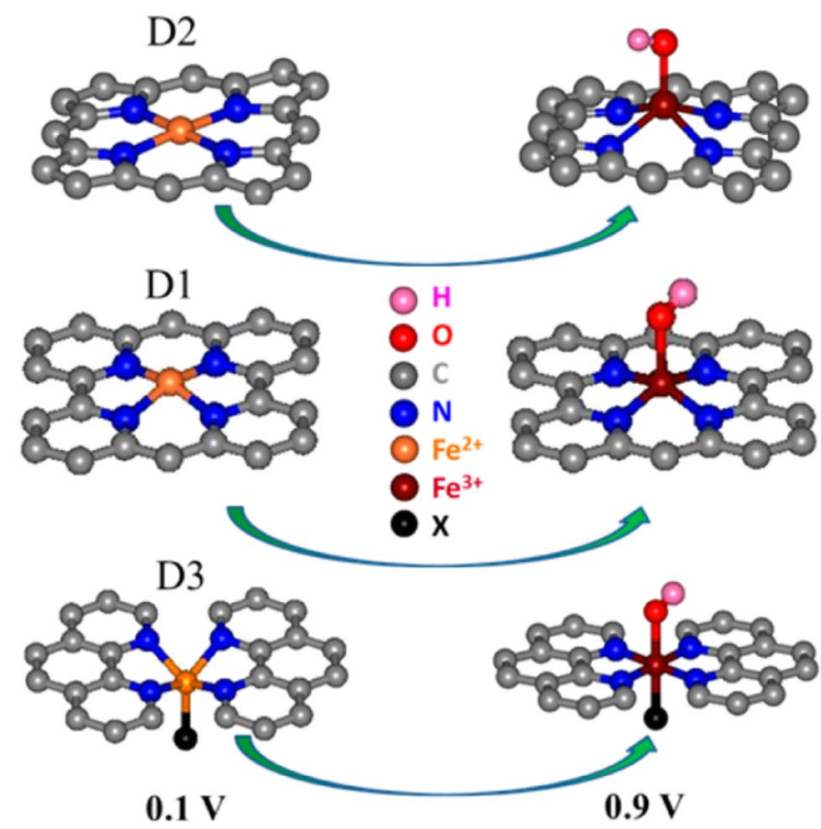

Fig. 6 Three different $\mathrm{Fe}^{\mathrm{II}} \mathrm{N}_{4}$ and $\mathrm{Fe}^{\mathrm{III}} \mathrm{N}_{4}$ structures of the pyrolyzed catalyst. Reprinted with permission from [180] metal centers with $\mathrm{N}$, the synthesis of $\mathrm{MN}_{4}$ structures, the introduction of more nonmetal elements and the formation of similar structures can all enhance SAC performances. Recently, $\mathrm{Li}$ et al. [181] also reported a simple impregnation-pyrolysis method to produce SACs with $\mathrm{M}-\mathrm{N}-\mathrm{P}-\mathrm{C}$ complex structures from biomass in which SACs with $\mathrm{Fe}$, $\mathrm{Co}, \mathrm{Ni}, \mathrm{Mn}$ and $\mathrm{Cr}$ metal centers were prepared by simply changing the metal precursor. As a result, the Fe-N-P-C material reportedly provided a high ORR activity comparable to that of most state-of-the-art transition metal catalysts. And by using DFT, XPS and XAFS, the structures of these $\mathrm{M}-\mathrm{N}-\mathrm{P}-\mathrm{C}$ catalysts and the catalytic reaction cycles were studied (Fig. 7) [182], revealing that similar to $\mathrm{MN}_{4}$ structures, the performance of $\mathrm{M}-\mathrm{N}-\mathrm{P}-\mathrm{C}$ composites was determined by metal centers in which ORR activity was in the order of: Fe-NPWB $>$ Co-NPWB $>\mathrm{Cu}-\mathrm{NPWB}>\mathrm{Mn}$ NPWB $>$ Ni-NPWB $>$ Cr-NPWB. Moreover, these researchers also reported that the ORR activity of these catalysts correlated to the 1 st ionization energy of each metal center.

\subsection{Metal-Free Catalysts}

The replacement of precious metals with transition metals is an effective method to reduce costs and improve performance in ORR catalysts. In addition, the use of functionalized carbon materials as supports can significantly reduce the amount of transition metals needed in corresponding catalysts. Aside from these methods, researchers have also reported that metal-free carbon materials can show ORR activity in alkaline electrolytes in which carbon nanomaterials have been recognized as ideal candidates for many applications including metal-free ORR catalysis due to

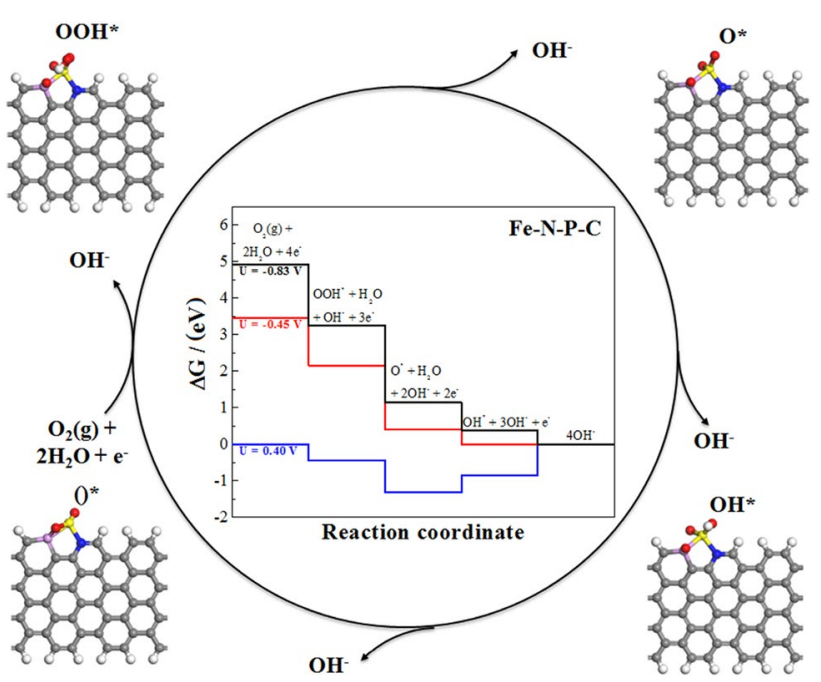

Fig. 7 Schematic of ORR on $\mathrm{Fe}-\mathrm{N}-\mathrm{P}-\mathrm{C}$ catalysts. The inset in the cycle shows the free energy diagram for ORR on this catalyst in alkali media. For $U<-0.45 \mathrm{~V}$ (vs. NHE), all steps were thermodynamically accessible. Reprinted with permission from [182] 

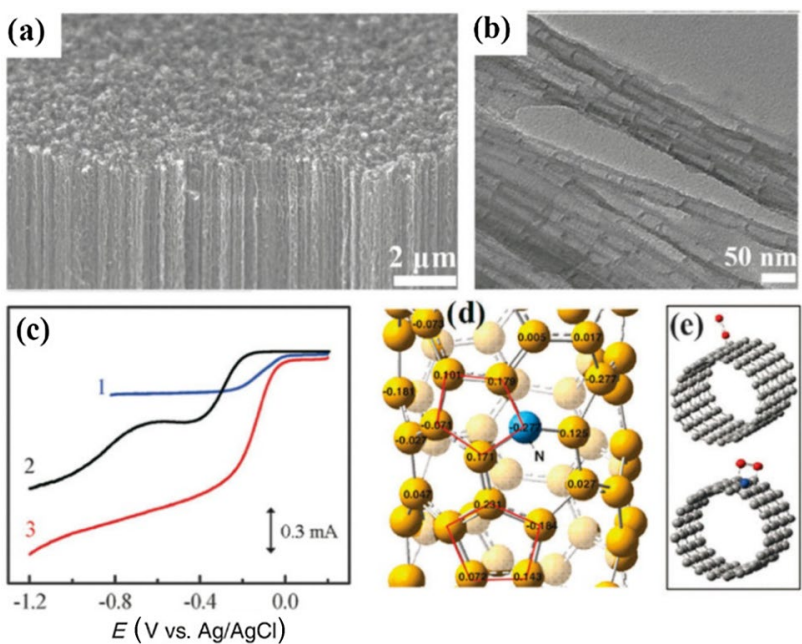

Fig. 8 a SEM image of as-synthesized VA-NCNTs on a quartz substrate. b TEM image of electrochemically purified VA-NCNTs. c Rotating ring disk electrode (RRDE) voltammograms for oxygen reduction in air saturated $0.1 \mathrm{M} \mathrm{KOH}$ at the Pt-C/GC (curve 1), CNT/GC (curve 2) and VA-NCNT (curve 3) electrodes. d Calculated charge density distribution for the NCNTs. e Schematics of possible adsorption modes of an oxygen molecule at the CCNT (top) and NCNT (bottom). Reprinted with permission from [186]

their unique surface and bulk properties, wide availability, environmental acceptability and corrosion resistance [183, 184]. In addition, various forms of carbon materials possess different electronic, optical, spectroscopic and electrochemical properties [38]. Furthermore, the introduction of heteroatoms such as $\mathrm{N}$ into the surface of carbon materials can further modify electron modulation and tune surface electronic structures, leading to efficient catalysts for different processes, including ORR [34].

\subsubsection{Single Heteroatom-Doped Carbon Materials}

Most pristine carbon materials show low catalytic activity for ORR in aqueous electrolytes [73], and although some catalytic ORR activity can be found in graphitic structured carbon materials with edge-plane sites, these usually present a two-step 2-electron pathway [38, 185]. Here, researchers have reported that one method to improve ORR activity is to introduce heteroatoms onto the surface of carbon materials, which can break the electroneutrality of carbon to create charged sites favorable for $\mathrm{O}_{2}$ adsorption and the effective utilization of carbon $\pi$ electrons for ORR [34].

Nitrogen-Doped Carbon Materials $\mathrm{N}$ is an efficient functional component or dopant for carbon materials that can be used to mitigate activity degradation and as a result has been intensively investigated [38]. For example, Gong et al. [186] found that vertically aligned $\mathrm{N}$-containing carbon nanotubes (VA-NCNTs, Fig. 8a, b) can act as a metal-free ORR catalyst and possessed improved electrocatalytic activity, long-term operation stability and high tolerance towards the crossover effects of methanol and $\mathrm{CO}$ poisoning. In addition, these researchers found that VA-NCNTs can even outperform commercial Pt/C catalysts in alkaline electrolytes (Fig. 8c) and attributed the improved electrocatalytic activity to the change in electronic structure during the doping of carbon nanotubes in which the incorporation of electron-accepting $\mathrm{N}$ atoms in the conjugated nanotube carbon plane can produce relatively high positive charge density on adjacent carbon atoms (Fig. 8d). And as a result of the synergistic effects of $\mathrm{N}$-doping and vertically aligned structure, superior ORR performances with a 4-electron pathway can be obtained.

The nature of active sites and ORR mechanisms for $\mathrm{N}$-containing carbon materials remain unclear due to the difficulty in selectively controlling the form of $\mathrm{N}$-groups [34, 38]. To address this, one possible method is to use organic precursors with well-defined uniform $\mathrm{N}$-containing structures as precursors for synthesis. However, the carbonization of these organic precursors can form $\mathrm{sp}^{2}$ carbon structures, which will generally lead to the migration of $\mathrm{N}$ atoms onto carbon surfaces, resulting in the formation of different $\mathrm{N}$-groups [187]. Recently, Guo et al. [188] addressed this issue by selectively introducing pyridinic $\mathrm{N}$ and graphitic $\mathrm{N}$ separately into highly oriented pyrolytic graphite (HOPG) and demonstrated that pyridinic N-dominated HOPG possessed relatively high ORR activity in acidic media and that ORR activity was linearly related to the concentration of pyridinic $\mathrm{N}$. These researchers also tested $\mathrm{CO}_{2}$ temperature programmed desorption and found that acidic $\mathrm{CO}_{2}$ molecules were only adsorbed on ORR active pyridinic $\mathrm{N}$ sites, suggesting that the introduction of pyridinic $\mathrm{N}$ sites can create Lewis basic sites on carbon adjacent to $\mathrm{N}$ atoms, leading to the proposal of a possible mechanism for ORR (Fig. 9).

Phosphorus-Doped Carbon Materials $\mathrm{P}$ possesses smaller electronegativity (2.19) and a larger atom size than carbon and has also been investigated as a possible element to substitute $\mathrm{sp}^{2}$ carbon atoms and modify electronic structures [34]. And although there have been many efforts to develop highly active ORR catalysts with P-doped carbon materials, the results have been underwhelming as compared with N-doped carbon materials [189-192]. One possible explanation for this is that $\mathrm{P}$ sites are far too active as compared with $\mathrm{N}$ sites, which hinders the removal of ORR intermediates from active site and thus slows down the overall reaction [193].

Boron-Doped Carbon Materials The use of B with an electronegativity of 2.04 to substitute carbon atoms can also break uniform charge density, and in the past decade, researchers have successfully synthesized B-doped carbon materials and employed them as ORR electrocatalysts [194-197]. Similar to P-doped carbons however, the performance of B-doped carbon materials is insufficient as compared with $\mathrm{N}$-doped carbon materials. For example, although 


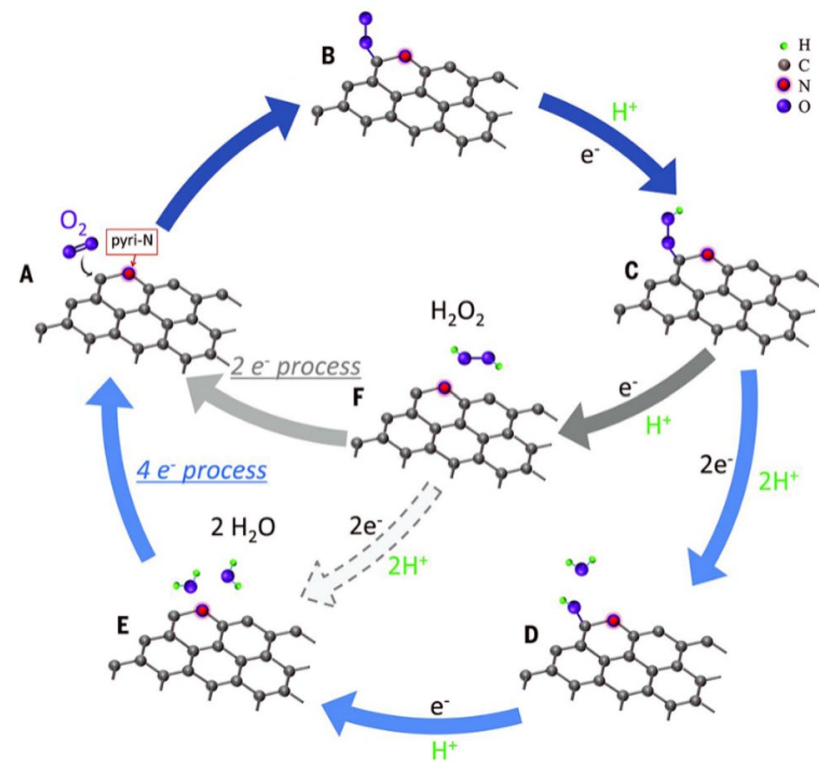

Fig. 9 Schematic pathway for ORR on N-doped carbon materials. Reprinted with permission from [188]

B-doped carbon nanotubes can exhibit excellent methanol and $\mathrm{CO}$ tolerances as compare with $\mathrm{Pt} / \mathrm{C}$ catalysts, ORR activities are insufficient [197].

\subsubsection{Multiple Heteroatom-Doped Carbon Materials}

The introduction of $\mathrm{N}$ atoms with an electronegativity of 3.04 into the $\mathrm{sp}^{2}$ lattice of carbon with an electronegativity of 2.55 can alter the charge neutrality of carbon materials and create active sites for ORR, allow for metal-free catalysts with good electrocatalytic ORR activities. In addition, the co-doping of mono-doped carbon materials with other nonmetal elements can further allow for the tuning of surface electronegativity. Therefore, the doping of additional elements into $\mathrm{N}$-doped carbon materials can provide the possibility to further tune electronic structures to obtain catalysts with even better ORR activities.

Boron and Nitrogen Co-Doped Carbon Materials The codoping of $\mathrm{N}$ and $\mathrm{B}$ can severely disturb the charge neutrality of carbon frameworks because $\mathrm{N}$ is an electron giver and $\mathrm{B}$ is an electron receiver [34] in which an early study demonstrated that the onset ORR potential of B and $\mathrm{N}$ co-doped carbon catalysts was $0.14 \mathrm{~V}$ higher than that of $\mathrm{N}$-doped carbon catalysts in acidic electrolytes and that $\mathrm{B}-\mathrm{N}-\mathrm{C}$ and edge- $\mathrm{N}$ surface structures were believed to synergistically contribute to overall activity $[198,199]$. For example, Wang et al. [200] co-doped VA-CNTs with B and N (VA-BCN) and reported that the resulting $\mathrm{B}$ and $\mathrm{N}$ co-doped catalyst possessed significantly enhanced performances as compared with N-doped VA-NCNTs and B-doped carbons (Fig. 10a). These researchers also compared LSV curves (Fig. 10b) and
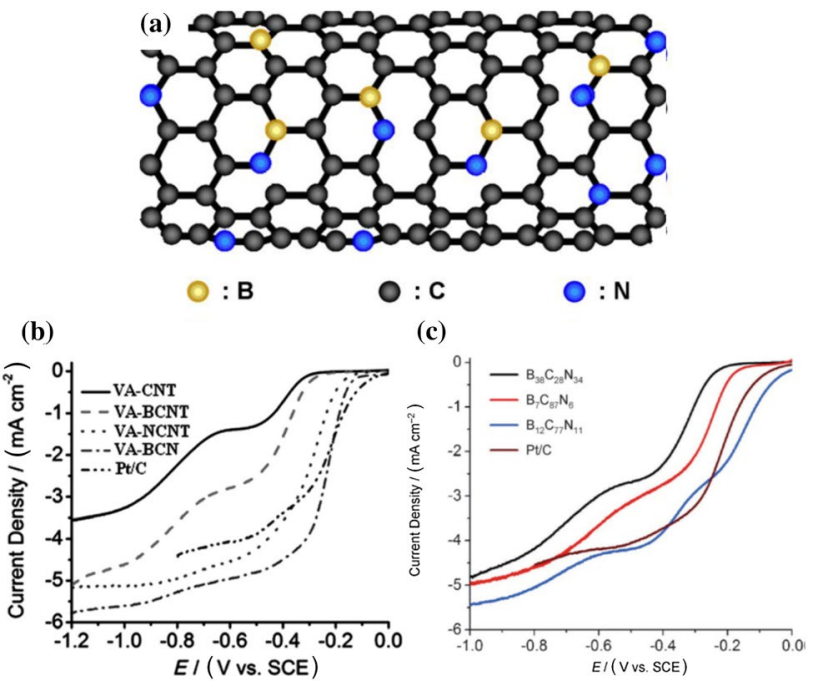

Fig. 10 a Schematic structure of VA-BCN and b LSV curves in an oxygen-saturated $0.1 \mathrm{M} \mathrm{KOH}$ electrolyte at a scan rate of $10 \mathrm{mV} / \mathrm{s}$ and a rotation rate of $1000 \mathrm{rpm}$. $\mathbf{c}$ LSV curves of ORR on BCN graphene with different compositions in oxygen-saturated $0.1 \mathrm{M} \mathrm{KOH}$ solution at $10 \mathrm{mV} \mathrm{s}^{-1}$. Reprinted with permission from [200, 201]

found that the $\mathrm{N}$-groups appeared to be able to increase the onset potential and limiting current, whereas the B-groups appeared to be only able to increase the limiting current rather than the onset potential. Furthermore, these researchers also optimized $\mathrm{B}$ and $\mathrm{N}$ content in $\mathrm{BCN}$ graphene in a later study and reported even better ORR performances than that of Pt/C (Fig. 10c). These researchers also reported that higher concentrations of B led to enlarged HOMO-LUMO gaps and reduced conductivity, thus hindering electron transfer kinetics. Therefore, the reduction of B content can result in smaller HOMO-LUMO gaps and higher limiting currents [201].

Phosphorus and Nitrogen Co-Doped Carbon Materials The co-doping of $\mathrm{P}$ and $\mathrm{N}$ into carbon frameworks can also severely disturb charge neutrality because $\mathrm{P}$ can act as an electron receiver. For example, Yu et al. [33] developed metal-free heteroatom-doped carbon catalysts for ORR and achieved superior ORR activities using $\mathrm{N}$ and $\mathrm{P}$ co-doped VA-CNTs (PN-ACNT) in which as compared with mono $\mathrm{N}$ - or P-doped CNTs, this PN-ACNT exhibited larger limiting currents and slightly higher onset potentials in alkaline media. Here, this synergistic effect was believed to be due to the promotion of $\mathrm{HO}^{2-}$ reduction by $\mathrm{P}$ within the overall potential range [34]. Furthermore, the understanding of local chemical interactions between $\mathrm{P}$ and $\mathrm{N}$ heteroatoms in carbon matrixes is important to elucidate catalytic mechanisms and better design electrocatalysts for ORR. Based on this, Zhang et al. [30] synthesized $\mathrm{N}$ and $\mathrm{P}$ co-doped carbon materials with less ordered structures through a polymerization-pyrolysis process using phytic acid and aniline as 

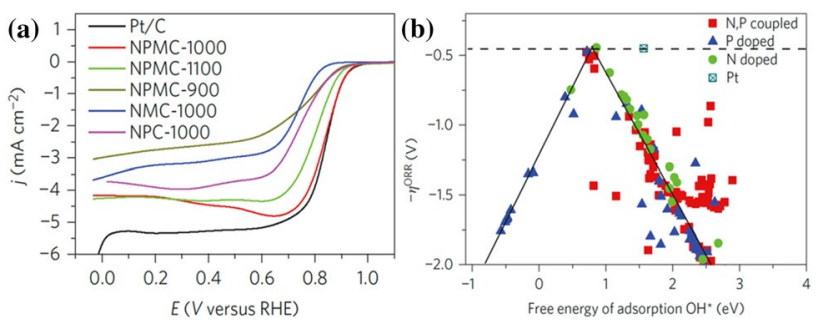

Fig. 11 a LSV curves for NPMC-900, NPMC-1000, NPMC-1100, NMC-1000, NPC-1000 and commercial Pt/C catalysts at an RDE $(1600 \mathrm{rpm})$ in $\mathrm{O}_{2}$-saturated $0.1 \mathrm{M} \mathrm{KOH}$ solution. Scan rate: $5 \mathrm{mV} / \mathrm{s}$. b ORR volcano plot of overpotential $\eta$ versus $\mathrm{OH}^{*}$ adsorption energy for $\mathrm{N}$-doped, P-doped and N, P co-doped graphene. Reprinted with permission from [30]

precursors to introduce $\mathrm{P}$ and $\mathrm{N}$. As a result, the resulting electrocatalyst (NPMC-1000) exhibited excellent ORR activities with onset and half-wave potentials of $0.94 \mathrm{~V}$ and $0.85 \mathrm{~V}$ vs. RHE, respectively (Fig. 11a), both of which are comparable to that of $\mathrm{Pt} / \mathrm{C}$ although the limiting current was only slightly lower than Pt/C. These researchers also determined the electronic structure and catalytic reaction of N, P co-doped carbon structures using computational simulations and obtained a volcano plot of the overpotential versus the free energy of $\mathrm{OH}^{*}$ adsorption for various reaction sites in alkaline environments (Fig. 11b). Here, N-doped, P-doped and $\mathrm{N}, \mathrm{P}$ co-doped structures were reported to possess minimum ORR overpotentials of $0.44,0.47$ and $0.47 \mathrm{~V}$, respectively, whereas the overall minimum ORR overpotential of $\mathrm{N}, \mathrm{P}$ co-doped graphene was $0.44 \mathrm{~V}$, which is lower than that of $\mathrm{Pt}(\sim 0.45 \mathrm{~V})$ [30], indicating that different doping structures were present on $\mathrm{N}, \mathrm{P}$ co-doped carbon and that all of these doping structures made contributions to overall ORR activity.

Sulfur and Nitrogen Co-Doped Carbon Materials The electronegativity of $\mathrm{S}$ atoms (2.58) is similar to that of carbon atoms (2.55) and the electron delocalization between them can be neglected [202]. However, in situations of codoping with $\mathrm{N}$, the small changes caused by $\mathrm{S}$ may allow for the tuning of surface properties in resultant catalysts. Because of this, many N and S co-doped metal-free ORR catalysts with different morphologies, surface properties and performances have been synthesized using different methods and a variety of precursors [202-208]. For example, Chen et al. [208] synthesized a N, S co-doped carbon beehive catalyst (NS-CB) through the pyrolysis of egg whites in $\mathrm{N}_{2}$ in the presence of molten $\mathrm{NaCl}$ and $\mathrm{KCl}$ salts. Here, egg whites were used as a precursor for $\mathrm{C}, \mathrm{N}$ and $\mathrm{S}$ whereas the molten salt environment facilitated the doping of $\mathrm{N}$ and $\mathrm{S}$ into the carbon matrix. And as a result, the resulting NS-CB provided an onset potential of $1.037 \mathrm{~V}$ versus RHE and a half-wave potential of $0.923 \mathrm{~V}$ versus RHE, both of which were comparable to those of $\mathrm{Pt} / \mathrm{C}$. In another example, Liang et al. [202] explored the effects of N, S co-doping on ORR activity and suggested that the spin density of an atom can determine the ability of the atom to become an active site in which if co-doped with $\mathrm{N}$ and $\mathrm{S}$, the spin density of carbon atoms bond to $\mathrm{N}$ (C1 in Fig. 12) can be significantly elevated. In addition, C2-C5 atoms can also be activated because $\mathrm{N}$ and $\mathrm{S}$ co-doping can induce asymmetrical spin and charge density. And due to both of these advantages, overall ORR activity can be enhanced.

\section{Summary, Technical Challenges and Possible Research Directions}

In the practical application of PEM fuel cells and metal-air batteries, the development of inexpensive and efficient electrocatalysts for cathodic ORR is essential. Therefore, this review has outlined the most recent progresses in this field and reviewed various types of electrocatalysts, including precious metal catalysts, NPMCs, SACs and metal-free catalysts. And to facilitate future research and development, existing technical challenges are summarized and possible future research directions are proposed as follows.

\subsection{Challenges}

To facilitate the large-scale application of PEM fuel cells and metal-air batteries, ORR electrocatalysts need to be highly active/stable and cost-effective. Here, a major challenge for precious metal catalysts is the reduction of precious metal usage while retaining ORR activity. And although alloys and core-shell structures of precious metals appear promising and can provide more active sites with limited precious metal atoms such as atomically dispersed atomic layers, the interactions between precious metals and

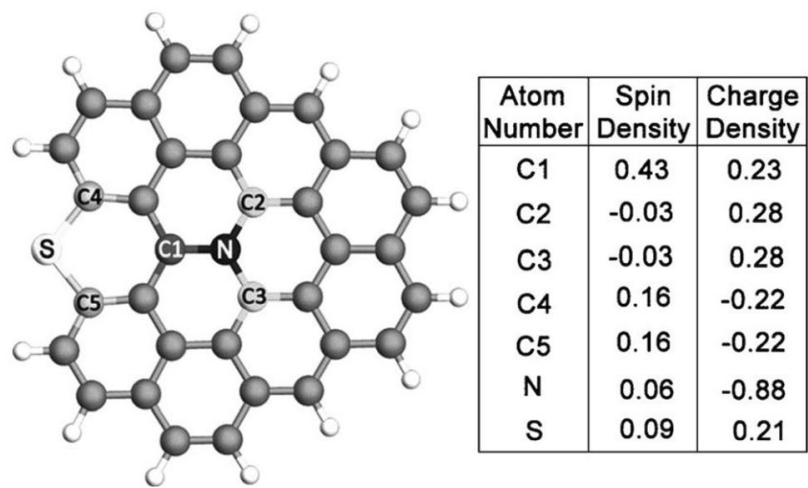

Fig. 12 Spin and charge density of a graphene network (gray) codoped by $\mathrm{N}$ (black) and $\mathrm{S}$ (white). $\mathrm{C} 1$ possesses high spin density, $\mathrm{C} 2$ and $\mathrm{C} 3$ possess high positive charge densities and $\mathrm{C} 4$ and $\mathrm{C} 5$ possess moderately high positive spin densities. Reprinted with permission from [202] 
inexpensive supporting alloys or underneath transition metals are not yet fully understood in terms of the tuning of precious metal electronic structures and the achievement of even higher ORR activities. Another challenge for precious metal catalysts is the insufficient stability in cases in which metal loading is low. And although SACs possess extremely low metal loadings and high metal utilization, their stability and ORR activity are low. As for NPMCs, high activity has been achieved in transition metal SACs, particularly SACs involving metal-nitrogen complexes with $\mathrm{Fe}$ or $\mathrm{Co}$ atom as metal centers. And of various NPMCs, $\mathrm{Fe}-\mathrm{N}_{x} / \mathrm{C}$ materials synthesized through pyrolysis appear to be the most promising due to the many advantages mentioned above. However, the syntheses of these metal-nitrogen complexes remain challenging due to metal oxides, metal carbides and other side products being produced in pyrolysis. These side products also make the isolation of $\mathrm{M}-\mathrm{N}_{x} / \mathrm{C}$ active sites difficult and limit ORR activity as well as the possibility of studying corresponding ORR mechanisms. Furthermore, the yield of single atoms is normally ignored in literature, which is evident due to the fact that increasing the yield of single atoms in $\mathrm{M}-\mathrm{N}_{x} / \mathrm{C}$ materials remains challenging. Moreover, the activity enhancement of $\mathrm{M}-\mathrm{N}_{x} / \mathrm{C}$ materials appears to have encountered a bottleneck and novel synthesis strategies are required to further improve both ORR activity and stability.

As for metal-free catalysts, the major challenge is the further enhancement of ORR activity and stability without the use of any metal(s) in which researchers have suggested that the high activity of many "metal-free" catalysts actually originates from trace metal impurities [209, 210]. In addition, carbon materials can decompose in extreme environments such as high electrode potentials, which needs to be addressed to allow for the potential application of these metal-free catalysts. Moreover, the actual active sites and catalytic mechanisms of metal-free catalysts remain unclear.

\subsection{Possible Research Directions}

To overcome the challenges mentioned above, future research directions on the development of cost-effective and efficient ORR electrocatalysts are proposed as follows:

1. The loading of precious metals needs to be further reduced and the activity and stability of these catalysts need to be further enhanced in which the particle size of precious metal catalysts with core-shell structures should be further reduced to construct active facets with less atoms. In addition, precious metal alloys should be confined in thin carbon layers to protect from dealloying and the interactions between carbon layers and precious metal alloys should be utilized to tune ORR activity.
2. The stability of SACs in practical applications needs to be improved. This can be achieved through doping strategies to generate synergistic effects to enhance catalytic ORR activity and through the fundamental understanding of catalytic mechanisms in SACs using both theoretical and experimental validations to design and optimize novel SACs.

3. The activity bottleneck of $\mathrm{M}-\mathrm{N}_{x} / \mathrm{C}$ materials needs to be resolved. Here, the partial substitution of $\mathrm{N}$ into $\mathrm{M}-$ $\mathrm{N}_{x} / \mathrm{C}$ structures with other nonmetal elements such as $\mathrm{B}$, $\mathrm{P}$ or $\mathrm{S}$ is a promising research direction. And because the ORR activity and stability of $\mathrm{M}-\mathrm{N}_{x} / \mathrm{C}$ materials are highly related to both the metal center species and its coordination environment, the precise tuning of $\mathrm{M}-\mathrm{N}_{x} / \mathrm{C}$ structures is also a promising research direction.

4. The creation of diatomic dispersed transition metal electrocatalysts. The alloying of two metal elements can alter the properties of each metal element due to interactions between them. These interactions also remain if only two atoms (one of each metal element) are presented. Therefore, the creation of active structures with two different transition metal atoms bond to each other can utilize both the interactions between the two metal atoms and between the metal atoms and the coordinating environment, thus allowing for the control of ORR activity and stability.

5. The "metal-free" of metal-free catalysts needs to be addressed. This way, the real origin of activity in metalfree catalysts can be revealed and the active sites and catalytic mechanisms of metal-free catalysts can be further clarified.

Acknowledgements The authors would like to acknowledge the support from the National Natural Science Foundation of China (51774100 and 51762006).

Open Access This article is distributed under the terms of the Creative Commons Attribution 4.0 International License (http://creativeco mmons.org/licenses/by/4.0/), which permits unrestricted use, distribution, and reproduction in any medium, provided you give appropriate credit to the original author(s) and the source, provide a link to the Creative Commons license, and indicate if changes were made.

\section{References}

1. Shafiee, S., Topal, E.: When will fossil fuel reserves be diminished? Energy Policy 37, 181-189 (2009). https://doi. org/10.1016/j.enpol.2008.08.016

2. Saheb Koussa, D., Koussa, M.: GHGs (greenhouse gases) emission and economic analysis of a GCRES (grid-connected renewable energy system) in the arid region, Algeria. Energy 102, 216-230 (2016). https://doi.org/10.1016/j.energy.2016.02.103 
3. The Renewable Route to Sustainable Transport: A Working Paper Based on REmap. In: International Renewable Energy Agency (IRENA), Abu Dhabi (2016)

4. Creutzig, F., Jochem, P., Edelenbosch, O.Y., et al.: Transport: a roadblock to climate change mitigation? Science 350, 911-912 (2015)

5. Wang, Y.J., Fang, B., Zhang, D., et al.: A review of carbon-composited materials as air-electrode bifunctional electrocatalysts for metal-air batteries. Electrochem. Energy Rev. 1, 1-34 (2018). https://doi.org/10.1007/s41918-018-0002-3

6. Wang, R., Wang, H., Luo, F., et al.: Core-shell-structured lowplatinum electrocatalysts for fuel cell applications. Electrochem. Energy Rev. 1, 324-387 (2018). https://doi.org/10.1007/s4191 8-018-0013-0

7. Wu, X., Zhu, W., Luo, K., et al.: Production of $\mathrm{NiFe}_{2} \mathrm{O}_{4}$ nanocermet for aluminium inert anode. Paper presented at the 146th TMS Annual Meeting and Exhibition/Conference on Light Metals, San Diego, CA, Feb 26-Mar 02, 2017

8. Yang, W.J., He, L.Q., Guo, J., et al.: Preparation and properties of a new ceramet inert anode for aluminum electrolysis. J. Adv. Microsc. Res. 12, 143-146 (2017)

9. Huang, H., Wei, X., Gao, S.: Nitrogen-doped porous carbon derived from malachium aquaticum biomass as a highly efficient electrocatalyst for oxygen reduction reaction. Electrochim. Acta 220, 427-435 (2016). https://doi.org/10.1016/j.elect acta.2016.10.108

10. Liu, Y., Ruan, J., Sang, S., et al.: Iron and nitrogen co-doped carbon derived from soybeans as efficient electro-catalysts for the oxygen reduction reaction. Electrochim. Acta 215, 388-397 (2016). https://doi.org/10.1016/j.electacta.2016.08.090

11. Zheng, X., Cao, X., Wu, J., et al.: Yolk-shell N/P/B ternarydoped biocarbon derived from yeast cells for enhanced oxygen reduction reaction. Carbon 107, 907-916 (2016). https://doi. org/10.1016/j.carbon.2016.06.102

12. Li, J., Zhang, Y., Zhang, X., et al.: S, N dual-doped graphene-like carbon nanosheets as efficient oxygen reduction reaction electrocatalysts. ACS Appl. Mater. Interfaces 9, 398-405 (2017). https ://doi.org/10.1021/acsami.6b12547

13. Chiwata, M., Yano, H., Ogawa, S., et al.: Oxygen reduction reaction activity of carbon-supported Pt-Fe, Pt-Co, and Pt-Ni alloys with stabilized Pt-skin layers. Electrochemistry 84, 133-137 (2016). https://doi.org/10.5796/electrochemistry.84.133

14. Raciti, D., Kubal, J., Ma, C., et al.: $\mathrm{Pt}_{3} \mathrm{Re}$ alloy nanoparticles as electrocatalysts for the oxygen reduction reaction. Nano Energy 20, 202-211 (2016). https://doi.org/10.1016/j.nanoe n.2015.12.014

15. Beermann, V., Gocyla, M., Willinger, E., et al.: Rh-doped Pt-Ni octahedral nanoparticles: understanding the correlation between elemental distribution, oxygen reduction reaction, and shape stability. Nano Lett. 16, 1719-1725 (2016). https://doi.org/10.1021/ acs.nanolett.5b04636

16. Zhang, J., Qu, L., Shi, G., et al.: N, P-codoped carbon networks as efficient metal-free bifunctional catalysts for oxygen reduction and hydrogen evolution reactions. Angew. Chem. Int. Ed. 55, 2230-2234 (2016). https://doi.org/10.1002/anie.201510495

17. Bai, X., Zhao, E., Li, K., et al.: Theoretical insights on the reaction pathways for oxygen reduction reaction on phosphorus doped graphene. Carbon 105, 214-223 (2016). https://doi. org/10.1016/j.carbon.2016.04.033

18. Ma, M., You, S., Wang, W., et al.: Biomass-derived porous $\mathrm{Fe}_{3} \mathrm{C} /$ tungsten carbide/graphitic carbon nanocomposite for efficient electrocatalysis of oxygen reduction. ACS Appl. Mater. Interfaces 8, 32307-32316 (2016). https://doi.org/10.1021/acsam i. $6 \mathrm{~b} 10804$
19. Wu, H., Geng, J., Ge, H., et al.: Egg-derived mesoporous carbon microspheres as bifunctional oxygen evolution and oxygen reduction electrocatalysts. Adv. Energy Mater. 6, 1600794 (2016). https://doi.org/10.1002/aenm.201600794

20. Song, L.T., Wu, Z.Y., Zhou, F., et al.: Sustainable hydrothermal carbonization synthesis of iron/nitrogen-doped carbon nanofiber aerogels as electrocatalysts for oxygen reduction. Small 12, 6398-6406 (2016). https://doi.org/10.1002/smll.201602334

21. Li, M., Liu, T., Fan, L., et al.: Three-dimensional hierarchical meso/macroporous $\mathrm{Fe} / \mathrm{Co}$-nitrogen-doped carbon encapsulated FeCo alloy nanoparticles prepared without any template or surfactant: high-performance bifunctional oxygen electrodes. J. Alloys Compd. 686, 467-478 (2016). https://doi.org/10.1016/j. jallcom.2016.06.060

22. Dai, L., Liu, M., Song, Y., et al.: $\mathrm{Mn}_{3} \mathrm{O}_{4}$-decorated $\mathrm{Co}_{3} \mathrm{O}_{4}$ nanoparticles supported on graphene oxide: dual electrocatalyst system for oxygen reduction reaction in alkaline medium. Nano Energy 27, 185-195 (2016). https://doi.org/10.1016/j.nanoe n.2016.07.007

23. Chen, X., Li, R., Wang, J., et al.: Spinel $\mathrm{MnCo}_{2} \mathrm{O}_{4} / \mathrm{N}, \mathrm{S}$-doped carbon nanotubes as an efficient oxygen reduction reaction electrocatalyst. ChemistrySelect 1, 2159-2162 (2016). https://doi. org/10.1002/slct.201600401

24. Lefèvre, M., Proietti, E., Jaouen, F., et al.: Iron-based catalysts with improved oxygen reduction activity in polymer electrolyte fuel cells. Science 324, 71-74 (2009)

25. Choi, C.H., Chung, M.W., Park, S.H., et al.: Additional doping of phosphorus and/or sulfur into nitrogen-doped carbon for efficient oxygen reduction reaction in acidic media. Phys. Chem. Chem. Phys. 15, 1802-1805 (2013). https://doi.org/10.1039/c2cp44147k

26. Yu, Y.N., Wang, M.Q., Bao, S.J.: Biomass-derived synthesis of nitrogen and phosphorus Co-doped mesoporous carbon spheres as catalysts for oxygen reduction reaction. J. Solid State Electrochem. 21, 103-110 (2016). https://doi.org/10.1007/s1000 8-016-3346-9

27. Lin, H., Chu, L., Wang, X., et al.: Boron, nitrogen, and phosphorous ternary doped graphene aerogel with hierarchically porous structures as highly efficient electrocatalysts for oxygen reduction reaction. New J. Chem. 40, 6022-6029 (2016). https://doi. org/10.1039/c5nj03390j

28. von Deak, D., Biddinger, E.J., Luthman, K.A., et al.: The effect of phosphorus in nitrogen-containing carbon nanostructures on oxygen reduction in PEM fuel cells. Carbon 48, 3637-3639 (2010). https://doi.org/10.1016/j.carbon.2010.05.022

29. Deng, C., Zhong, H., Li, X., et al.: A highly efficient electrocatalyst for oxygen reduction reaction: phosphorus and nitrogen co-doped hierarchically ordered porous carbon derived from an iron-functionalized polymer. Nanoscale 8, 1580-1587 (2016). https://doi.org/10.1039/c5nr06749a

30. Zhang, J., Zhao, Z., Xia, Z., et al.: A metal-free bifunctional electrocatalyst for oxygen reduction and oxygen evolution reactions. Nat. Nanotechnol. 10, 444-452 (2015). https://doi.org/10.1038/ nnano. 2015.48

31. Jiang, H., Zhu, Y., Feng, Q., et al.: Nitrogen and phosphorus dual-doped hierarchical porous carbon foams as efficient metalfree electrocatalysts for oxygen reduction reactions. Chemistry 20, 3106-3112 (2014). https://doi.org/10.1002/chem.201304561

32. Choi, C.H., Park, S.H., Woo, S.I.: Phosphorus-nitrogen dual doped carbon as an effective catalyst for oxygen reduction reaction in acidic media: effects of the amount of P-doping on the physical and electrochemical properties of carbon. J. Mater. Chem. 22, 12107 (2012). https://doi.org/10.1039/c2jm31079a

33. Yu, D., Xue, Y., Dai, L.: Vertically aligned carbon nanotube arrays co-doped with phosphorus and nitrogen as efficient 
metal-free electrocatalysts for oxygen reduction. J. Phys. Chem. Lett. 3, 2863-2870 (2012). https://doi.org/10.1021/jz3011833

34. Wang, D.W., Su, D.: Heterogeneous nanocarbon materials for oxygen reduction reaction. Energy Environ. Sci. 7, 576 (2014). https://doi.org/10.1039/c3ee43463j

35. Yu, L., Pan, X., Cao, X., et al.: Oxygen reduction reaction mechanism on nitrogen-doped graphene: a density functional theory study. J. Catal. 282, 183-190 (2011). https://doi.org/10.1016/j. jcat.2011.06.015

36. Chen, X., Yu, L., Wang, S., et al.: Highly active and stable single iron site confined in graphene nanosheets for oxygen reduction reaction. Nano Energy 32, 353-358 (2017). https://doi. org/10.1016/j.nanoen.2016.12.056

37. Zhang, L., Li, H., Zhang, J.: Kinetics of oxygen reduction reaction on three different Pt surfaces of $\mathrm{Pt} / \mathrm{C}$ catalyst analyzed by rotating ring-disk electrode in acidic solution. J. Power Sources 255, 242-250 (2014). https://doi.org/10.1016/j.jpows our.2014.01.042

38. Cheng, F., Chen, J.: Metal-air batteries: from oxygen reduction electrochemistry to cathode catalysts. Chem. Soc. Rev. 41, 2172-2192 (2012). https://doi.org/10.1039/c1cs15228a

39. Wei, S.Z., Kibsgaard, J., Dickens, C.F., et al.: Combining theory and experiment in electrocatalysis: insights into materials design. Science 355, eaad4998 (2017). https://doi.org/10.1126/scien ce.aad4998

40. Lim, B., Jiang, M., Camargo, P.H., et al.: Pd-Pt bimetallic nanodendrites with high activity for oxygen reduction. Science 324, 1302-1305 (2009)

41. Yamamoto, K., Imaoka, T., Chun, W.J., et al.: Size-specific catalytic activity of platinum clusters enhances oxygen reduction reactions. Nat. Chem. 1, 397-402 (2009). https://doi. org/10.1038/nchem.288

42. Zhang, J., Vukmirovic, M.B., Xu, Y., et al.: Controlling the catalytic activity of platinum-monolayer electrocatalysts for oxygen reduction with different substrates. Angew. Chem. Int. Ed. 44, 2132-2135 (2005). https://doi.org/10.1002/anie.200462335

43. Sui, S., Wang, X., Zhou, X., et al.: A comprehensive review of Pt electrocatalysts for the oxygen reduction reaction: nanostructure, activity, mechanism and carbon support in PEM fuel cells. J. Mater. Chem. A 5, 1808-1825 (2017)

44. Wu, K.H., Shi, W., Wang, D., et al.: In situ electrostatic modulation of path selectivity for the oxygen reduction reaction on $\mathrm{Fe}-\mathrm{N}$ doped carbon catalyst. Chem. Mater. 29, 4649-4653 (2017). https://doi.org/10.1021/acs.chemmater.7b01619

45. Jung, N., Sohn, Y., Park, J.H., et al.: High-performance PtCux@ Pt core-shell nanoparticles decorated with nanoporous Pt surfaces for oxygen reduction reaction. Appl. Catal. B 196, 199-206 (2016). https://doi.org/10.1016/j.apcatb.2016.05.028

46. Kuttiyiel, K.A., Choi, Y., Sasaki, K., et al.: Tuning electrocatalytic activity of Pt monolayer shell by bimetallic Ir-M $(\mathrm{M}=\mathrm{Fe}$ $\mathrm{Co}, \mathrm{Ni}$ or $\mathrm{Cu}$ ) cores for the oxygen reduction reaction. Nano Energy (2016). https://doi.org/10.1016/j.nanoen.2016.05.024

47. Cai, B., Hübner, R., Sasaki, K., et al.: Core-shell structuring of pure metallic aerogels towards highly efficient platinum utilization for the oxygen reduction reaction. Angew. Chem. Int. Ed. 57, 2963-2966 (2018)

48. Xiong, Y., Shan, H., Zhou, Z., et al.: Tuning surface structure and strain in Pd-Pt core-shell nanocrystals for enhanced electrocatalytic oxygen reduction. Small 13, 1603423 (2017)

49. Tian, X., Tang, H., Luo, J., et al.: High-performance core-shell catalyst with nitride nanoparticles as a core: well-defined titanium copper nitride coated with an atomic $\mathrm{Pt}$ layer for the oxygen reduction reaction. ACS Catal. 7, 3810-3817 (2017)

50. Stamenkovic, V.R., Mun, B.S., Arenz, M., et al.: Trends in electrocatalysis on extended and nanoscale Pt-bimetallic alloy surfaces. Nat. Mater. 6(3), 241-247 (2007). https://doi. org/10.1038/nmat 1840

51. Coleman, E.J., Chowdhury, M.H., Co, A.C.: Insights into the oxygen reduction reaction activity of $\mathrm{Pt} / \mathrm{C}$ and $\mathrm{PtCu} / \mathrm{C}$ catalysts. ACS Catal. 5, 1245-1253 (2015). https://doi.org/10.1021/cs501 $762 \mathrm{~g}$

52. Jiang, K., Zhao, D., Guo, S., et al.: Efficient oxygen reduction catalysis by subnanometer Pt alloy nanowires. Sci. Adv. 3, e1601705 (2017)

53. Jensen, K.D., Tymoczko, J., Rossmeisl, J., et al.: Elucidation of the oxygen reduction volcano in alkaline media using a copper-platinum (111) alloy. Angew. Chem. Int. Ed. 57, 2800-2805 (2018)

54. Roy, C., Knudsen, B.P., Pedersen, C.M., et al.: Scalable synthesis of carbon-supported platinum-lanthanide and-rare-earth alloys for oxygen reduction. ACS Catal. 8, 2071-2080 (2018)

55. Kobayashi, S., Aoki, M., Wakisaka, M., et al.: Atomically flat Pt skin and striking enrichment of Co in underlying alloy at $\mathrm{Pt}_{3} \mathrm{Co}$ (111) single crystal with unprecedented activity for the oxygen reduction reaction. ACS Omega 3, 154-158 (2018)

56. Nie, Y., Li, L., Wei, Z.: Recent advancements in Pt and Pt-free catalysts for oxygen reduction reaction. Chem. Soc. Rev. 44, 2168-2201 (2015)

57. Stacy, J., Regmi, Y.N., Leonard, B., et al.: The recent progress and future of oxygen reduction reaction catalysis: a review. Renew. Sustain. Energy Rev. 69, 401-414 (2017)

58. Shao, M., Chang, Q., Dodelet, J.P., et al.: Recent advances in electrocatalysts for oxygen reduction reaction. Chem. Rev. 116, 3594-3657 (2016). https://doi.org/10.1021/acs.chemrev.5b00462

59. Wang, Y.J., Zhao, N., Fang, B., et al.: Carbon-supported Pt-based alloy electrocatalysts for the oxygen reduction reaction in polymer electrolyte membrane fuel cells: particle size, shape, and composition manipulation and their impact to activity. Chem. Rev. 115, 3433-3467 (2015). https://doi.org/10.1021/cr500519c

60. Jeon, T.Y., Yoo, S.J., Cho, Y.H., et al.: Influence of oxide on the oxygen reduction reaction of carbon-supported $\mathrm{Pt}-\mathrm{Ni}$ alloy nanoparticles. J. Phys. Chem. C 113, 19732-19739 (2009)

61. Markovic, N., Schmidt, T., Stamenkovic, V., et al.: Oxygen reduction reaction on $\mathrm{Pt}$ and $\mathrm{Pt}$ bimetallic surfaces: a selective review. Fuel Cells 1, 105-116 (2001)

62. Hwang, S.J., Kim, S.K., Lee, J.G., et al.: Role of electronic perturbation in stability and activity of Pt-based alloy nanocatalysts for oxygen reduction. J. Am. Chem. Soc. 134, 19508-19511 (2012). https://doi.org/10.1021/ja307951y

63. Stephens, I.E.L., Bondarenko, A.S., Grønbjerg, U., et al.: Understanding the electrocatalysis of oxygen reduction on platinum and its alloys. Energy Environ. Sci. 5, 6744 (2012). https://doi. org/10.1039/c2ee03590a

64. Nørskov, J.K., Rossmeisl, J., Logadottir, A., et al.: Origin of the overpotential for oxygen reduction at a fuel-cell cathode. J. Phys. Chem. B 108, 17886-17892 (2004)

65. Greeley, J., Stephens, I.E., Bondarenko, A.S., et al.: Alloys of platinum and early transition metals as oxygen reduction electrocatalysts. Nat. Chem. 1, 552-556 (2009). https://doi.org/10.1038/ nchem.367

66. Freund, R., Lächelt, U., Gruber, T., et al.: Multifunctional efficiency: extending the concept of atom economy to functional nanomaterials. ACS Nano 12, 2094-2105 (2018)

67. Trost, B.M.: The atom economy-a search for synthetic efficiency. Science 254, 1471-1477 (1991)

68. Strasser, P., Koh, S., Anniyev, T., et al.: Lattice-strain control of the activity in dealloyed core-shell fuel cell catalysts. Nat. Chem. 2, 454-460 (2010). https://doi.org/10.1038/nchem.623

69. Omura, J., Yano, H., Tryk, D.A., et al.: Electrochemical quartz crystal microbalance analysis of the oxygen reduction reaction 
on Pt-based electrodes. Part 2: adsorption of oxygen species and $\mathrm{ClO} 4(-)$ anions on $\mathrm{Pt}$ and $\mathrm{Pt}-\mathrm{Co}$ alloy in $\mathrm{HClO}_{4}$ solutions. Langmuir 30, 432-439 (2014). https://doi.org/10.1021/la404188p

70. Huang, Y., Zhang, J., Kongkanand, A., et al.: Transient platinum oxide formation and oxygen reduction on carbon-supported platinum and platinum-cobalt alloy electrocatalysts. J. Electrochem. Soc. 161, F10-F15 (2014)

71. Chen, Z., Dodelet, J.P., Zhang, J.: Non-noble metal Catalysts for Oxygen Reduction. Wiley, New York (2014)

72. Zhang, L., Wilkinson, D.P., Liu, Y., et al.: Progress in nanostructured ( $\mathrm{Fe}$ or $\mathrm{Co}) / \mathrm{N} / \mathrm{C}$ non-noble metal electrocatalysts for fuel cell oxygen reduction reaction. Electrochim. Acta 262, 326-336 (2018)

73. Wang, Z.L., Xu, D., Xu, J.J., et al.: Oxygen electrocatalysts in metal-air batteries: from aqueous to nonaqueous electrolytes. Chem. Soc. Rev. 43, 7746-7786 (2014). https://doi.org/10.1039/ c3cs60248f

74. Żółtowski, P., Dražić, D., Vorkapić, L.: Carbon-air electrode with regenerative short time overload capacity: Part 1. Effect of manganese dioxide. J. Appl. Electrochem. 3, 271-283 (1973)

75. Yang, H., Hu, F., Zhang, Y., et al.: Controlled synthesis of porous spinel cobalt manganese oxides as efficient oxygen reduction reaction electrocatalysts. Nano Res. 9, 207-213 (2016). https:// doi.org/10.1007/s12274-016-0982-4

76. Zuo, L.X., Jiang, L.P., Abdel-Halim, E.S., et al.: Sonochemical preparation of stable porous $\mathrm{MnO}_{2}$ and its application as an efficient electrocatalyst for oxygen reduction reaction. Ultrason. Sonochem. 35, 219-225 (2017). https://doi.org/10.1016/j.ultso nch.2016.09.021

77. Lehtimäki, M., Hoffmannová, H., Boytsova, O., et al.: Targeted design of $\alpha-\mathrm{MnO}_{2}$ based catalysts for oxygen reduction. Electrochim. Acta 191, 452-461 (2016). https://doi.org/10.1016/j.elect acta.2016.01.070

78. Mosa, I.M., Biswas, S., El-Sawy, A.M., et al.: Tunable mesoporous manganese oxide for high performance oxygen reduction and evolution reactions. J. Mater. Chem. A 4, 620-631 (2016). https://doi.org/10.1039/c5ta07878d

79. Cheng, F., Su, Y., Liang, J., et al.: $\mathrm{MnO}_{2}$-based nanostructures as catalysts for electrochemical oxygen reduction in alkaline media. Chem. Mater. 22, 898-905 (2010). https://doi.org/10.1021/ cm901698s

80. Zeng, Z., Zhang, W., Liu, Y., et al.: Uniformly electrodeposited $\alpha-\mathrm{MnO}_{2}$ film on super-aligned electrospun carbon nanofibers for a bifunctional catalyst design in oxygen reduction reaction. Electrochim. Acta 256, 232-240 (2017)

81. Delmondo, L., Munoz-Tabares, J., Sacco, A., et al.: Thermal evolution of $\mathrm{Mn}_{x} \mathrm{O}_{y}$ nanofibres as catalysts for the oxygen reduction reaction. Phys. Chem. Chem. Phys. 19, 28781-28787 (2017)

82. Roche, I., Chaînet, E., Chatenet, M., et al.: Carbon-supported manganese oxide nanoparticles as electrocatalysts for the oxygen reduction reaction (ORR) in alkaline medium: physical characterizations and ORR mechanism. J. Phys. Chem. C 111, 1434-1443 (2007)

83. Risch, M., Stoerzinger, K.A., Han, B., et al.: Redox processes of manganese oxide in catalyzing oxygen evolution and reduction: an in situ soft X-ray absorption spectroscopy study. J. Phys. Chem. C 121, 17682-17692 (2017)

84. Zhang, T., Li, Z., Sun, P., et al.: $\alpha-\mathrm{MnO}_{2}$ nanorods supported on three dimensional graphene as high activity and durability cathode electrocatalysts for magnesium-air fuel cells. Catal. Today (2019). https://doi.org/10.1016/j.cattod.2019.04.055

85. Ojha, G.P., Gautam, J., Muthurasu, A., et al.: In-situ fabrication of manganese oxide nanorods decorated manganese oxide nanosheets as an efficient and durable catalyst for oxygen reduction reaction. Colloids Surf. A 568, 311-318 (2019). https //doi.org/10.1016/j.colsurfa.2019.02.030

86. Xiang, W., Zhao, Y., Jiang, Z., et al.: Palladium single atoms supported by interwoven carbon nanotube and manganese oxide nanowire networks for enhanced electrocatalysis. J. Mater. Chem. A 6, 23366-23377 (2018). https://doi.org/10.1039/c8ta09034c

87. Yang, J., Wang, J., Ma, S., et al.: Insight into the effect of crystalline structure on the oxygen reduction reaction activities of one-dimensional $\mathrm{MnO}_{2}$. Physica E 109, 191-197 (2019). https ://doi.org/10.1016/j.physe.2018.07.032

88. Zhang, T., Zhang, S., Cao, S., et al.: A self-templating redoxmediated synthesis of hollow phosphated manganese oxide nanospheres as noble-metal-like oxygen electrocatalysts. Chem. Mater. 30, 8270-8279 (2018). https://doi.org/10.1021/acs.chemm ater. $8 \mathrm{~b} 03681$

89. Xu, J., Gao, P., Zhao, T.S.: Non-precious $\mathrm{Co}_{3} \mathrm{O}_{4}$ nano-rod electrocatalyst for oxygen reduction reaction in anion-exchange membrane fuel cells. Energy Environ. Sci. 5, 5333-5339 (2012). https ://doi.org/10.1039/c1ee01431e

90. He, X., Yin, F., Li, G.: A Co/metal-organic-framework bifunctional electrocatalyst: the effect of the surface cobalt oxidation state on oxygen evolution/reduction reactions in an alkaline electrolyte. Int. J. Hydrog. Energy 40, 9713-9722 (2015). https://doi. org/10.1016/j.ijhydene.2015.06.027

91. Osgood, H., Devaguptapu, S.V., Xu, H., et al.: Transition metal ( $\mathrm{Fe} \mathrm{Co}, \mathrm{Ni}$, and $\mathrm{Mn}$ ) oxides for oxygen reduction and evolution bifunctional catalysts in alkaline media. Nano Today 11, 601-625 (2016). https://doi.org/10.1016/j.nantod.2016.09.001

92. Ryabova, A.S., Bonnefont, A., Simonov, P.A., et al.: Further insights into the role of carbon in manganese oxide/carbon composites in the oxygen reduction reaction in alkaline media. Electrochim. Acta 246, 643-653 (2017)

93. Tong, Y., Chen, P., Zhou, T., et al.: A bifunctional hybrid electrocatalyst for oxygen reduction and evolution: cobalt oxide nanoparticles strongly coupled to B, N-decorated graphene. Angew. Chem. 129, 7227-7231 (2017)

94. Wu, Z.S., Yang, S., Sun, Y., et al.: 3D nitrogen-doped graphene aerogel-supported $\mathrm{Fe}_{3} \mathrm{O}_{4}$ nanoparticles as efficient electrocatalysts for the oxygen reduction reaction. J. Am. Chem. Soc. 134, 9082-9085 (2012)

95. Shahid, M.M., Rameshkumar, P., Basirun, W.J., et al.: Cobalt oxide nanocubes interleaved reduced graphene oxide as an efficient electrocatalyst for oxygen reduction reaction in alkaline medium. Electrochim. Acta 237, 61-68 (2017)

96. Al-Hakemy, A.Z., Nassr, A.B.A.A., Naggar, A.H., et al.: Electrodeposited cobalt oxide nanoparticles modified carbon nanotubes as a non-precious catalyst electrode for oxygen reduction reaction. J. Appl. Electrochem. 47, 183-195 (2017)

97. Wei, C., Feng, Z., Scherer, G.G., et al.: Cations in octahedral sites: a descriptor for oxygen electrocatalysis on transition-metal spinels. Adv. Mater. (2017). https://doi.org/10.1002/adma.20160 6800

98. Pletcher, D., Li, X., Price, S.W.T., et al.: Comparison of the spinels $\mathrm{Co}_{3} \mathrm{O}_{4}$ and $\mathrm{NiCo}_{2} \mathrm{O}_{4}$ as bifunctional oxygen catalysts in alkaline media. Electrochim. Acta 188, 286-293 (2016). https:// doi.org/10.1016/j.electacta.2015.10.020

99. Lee, D.U., Li, J., Park, M.G., et al.: Self-assembly of spinel nanocrystals into mesoporous spheres as bifunctionally active oxygen reduction and evolution electrocatalysts. Chemsuschem (2017). https://doi.org/10.1002/cssc.201700369

100. Wu, G., Wang, J., Ding, W., et al.: A strategy to promote the electrocatalytic activity of spinels for oxygen reduction by structure reversal. Angew. Chem. Int. Ed. 55, 1340-1344 (2016)

101. Zhang, T., Li, Z., Wang, L., et al.: Spinel $\mathrm{MnCo}_{2} \mathrm{O}_{4}$ nanoparticles supported on three-dimensional graphene with enhanced mass 
transfer as an efficient electrocatalyst for oxygen reduction reaction. Chemsuschem 11, 2730-2736 (2018)

102. Zhou, Y., Sun, S., Xi, S., et al.: Superexchange effects on oxygen reduction activity of edge-sharing $\left[\mathrm{Co}_{x} \mathrm{Mn}_{1-x} \mathrm{O}_{6}\right]$ octahedra in spinel oxide. Adv. Mater. 30, 1705407 (2018)

103. Sickafus, K.E., Wills, J.M., Grimes, N.W.: Structure of spinel. J. Am. Ceram. Soc. 82, 3279-3292 (1999)

104. Zhang, T., Li, Z., Wang, L., et al.: Spinel $\mathrm{CoFe}_{2} \mathrm{O}_{4}$ supported by three dimensional graphene as high-performance bi-functional electrocatalysts for oxygen reduction and evolution reaction. Int. J. Hydrog. Energy 44, 1610-1619 (2019). https://doi. org/10.1016/j.ijhydene.2018.11.120

105. Rios, E., Gautier, J.L., Poillerat, G., et al.: Mixed valency spinel oxides of transition metals and electrocatalysis: case of the $\mathrm{Mn}_{x} \mathrm{Co}_{3-x} \mathrm{O}_{4}$ system. Electrochim. Acta 44, 1491-1497 (1998)

106. Liu, Y., Tan, X., Li, K.: Mixed conducting ceramics for catalytic membrane processing. Catal. Rev. 48, 145-198 (2006). https://doi.org/10.1080/01614940600631348

107. Jun, A., Kim, J., Shin, J., et al.: Perovskite as a cathode material: a review of its role in solid-oxide fuel cell technology. ChemElectroChem 3, 511-530 (2016). https://doi.org/10.1002/ celc. 201500382

108. Pena, M., Fierro, J.: Chemical structures and performance of perovskite oxides. Chem. Rev. 101, 1981-2018 (2001)

109. Sunarso, J., Torriero, A.A.J., Zhou, W., et al.: Oxygen reduction reaction activity of la-based perovskite oxides in alkaline medium: a thin-film rotating ring-disk electrode study. J. Phys. Chem. C 116, 5827-5834 (2012). https://doi.org/10.1021/ jp211946n

110. Suntivich, J., Gasteiger, H.A., Yabuuchi, N., et al.: Design principles for oxygen-reduction activity on perovskite oxide catalysts for fuel cells and metal-air batteries. Nat. Chem. 3, 546-550 (2011). https://doi.org/10.1038/nchem.1069

111. Arjun, N., Pan, G.T., Yang, T.C.K.: The exploration of Lanthanum based perovskites and their complementary electrolytes for the supercapacitor applications. Results Phys. 7, 920-926 (2017). https://doi.org/10.1016/j.rinp.2017.02.013

112. Duan, Q., Wang, J., Ding, C., et al.: Partial oxidation of methane over Ni based catalyst derived from order mesoporous $\mathrm{LaNiO}_{3}$ perovskite prepared by modified nanocasting method. Fuel 193, 112-118 (2017). https://doi.org/10.1016/j. fuel.2016.12.033

113. Pan, K.L., Chen, M.C., Yu, S.J., et al.: Enhancement of nitric oxide decomposition efficiency achieved with lanthanum-based perovskite-type catalyst. J. Air Waste Manag. Assoc. 66, 619630 (2016). https://doi.org/10.1080/10962247.2016.1158133

114. Zhang, C., Wang, C., Hua, W., et al.: Relationship between catalytic deactivation and physicochemical properties of $\mathrm{LaMnO}_{3}$ perovskite catalyst during catalytic oxidation of vinyl chloride. Appl. Catal. B 186, 173-183 (2016). https://doi.org/10.1016/j. apcatb.2015.12.052

115. Zhou, Z., Liu, X., Zhao, B., et al.: Elemental mercury oxidation over manganese-based perovskite-type catalyst at low temperature. Chem. Eng. J. 288, 701-710 (2016). https://doi. org/10.1016/j.cej.2015.12.057

116. Abreu-Sepulveda, M.A., Dhital, C., Huq, A., et al.: The influence of Fe substitution in lanthanum calcium cobalt oxide on the oxygen evolution reaction in alkaline media. J. Electrochem. Soc. 163, F1124-F1132 (2016)

117. Mazza, F., Trassatti, S.: Tungsten, titanium, and tantalum carbides and titanium nitrides as electrodes in redox systems. J. Electrochem. Soc. 110, 847-849 (1963)

118. Neburchilov, V., Wang, H., Martin, J.J., et al.: A review on air cathodes for zinc-air fuel cells. J. Power Sources 195, 1271-1291 (2010). https://doi.org/10.1016/j.jpowsour.2009.08.100
119. Zhong, H., Zhang, H., Liu, G., et al.: A novel non-noble electrocatalyst for PEM fuel cell based on molybdenum nitride. Electrochem. Commun. 8, 707-712 (2006). https://doi.org/10.1016/j. elecom.2006.02.020

120. Qi, J., Jiang, L., Jiang, Q., et al.: Theoretical and experimental studies on the relationship between the structures of molybdenum nitrides and their catalytic activities toward the oxygen reduction reaction. J. Phys. Chem. C 114, 18159-18166 (2010)

121. Xia, D., Liu, S., Wang, Z., et al.: Methanol-tolerant MoN electrocatalyst synthesized through heat treatment of molybdenum tetraphenylporphyrin for four-electron oxygen reduction reaction. J. Power Sources 177, 296-302 (2008). https://doi.org/10.1016/j. jpowsour.2007.11.050

122. Yuan, Y., Yang, L., He, B., et al.: Cobalt-zinc nitride on nitrogen doped carbon black nanohybrids as a non-noble metal electrocatalyst for oxygen reduction reaction. Nanoscale 9, 6259-6263 (2017)

123. Fan, Y., Ida, S., Staykov, A., et al.: Ni-Fe nitride nanoplates on nitrogen-doped graphene as a synergistic catalyst for reversible oxygen evolution reaction and rechargeable $\mathrm{Zn}$-Air battery. Small 13, 1700099 (2017)

124. Wang, K., Xiao, P., Liu, Y., et al.: Rational design and synthesis of sandwich-like iron nitride-graphene composites as efficient catalysts for oxygen reduction reaction. Int. J. Hydrog. Energy 42, 202-211 (2017)

125. Yin, H., Zhang, C., Liu, F., et al.: Hybrid of iron nitride and nitrogen-doped graphene aerogel as synergistic catalyst for oxygen reduction reaction. Adv. Funct. Mater. 24, 2930-2937 (2014)

126. Wang, Y., Fan, H., Ignaszak, A., et al.: Compositing doped-carbon with metals, non-metals, metal oxides, metal nitrides and other materials to form bifunctional electrocatalysts to enhance metal-air battery oxygen reduction and evolution reactions. Chem. Eng. J. 348, 416-437 (2018). https://doi.org/10.1016/j. cej.2018.04.208

127. Wang, M., Yang, Y., Liu, X., et al.: The role of iron nitrides in the $\mathrm{Fe}-\mathrm{N}-\mathrm{C}$ catalysis system towards the oxygen reduction reaction. Nanoscale 9, 7641-7649 (2017)

128. Wu, H., Chen, W.: Copper nitride nanocubes: size-controlled synthesis and application as cathode catalyst in alkaline fuel cells. J. Am. Chem. Soc. 133, 15236-15239 (2011). https://doi. org/10.1021/ja204748u

129. Dong, S., Chen, X., Zhang, X., et al.: Nanostructured transition metal nitrides for energy storage and fuel cells. Coord. Chem. Rev. 257, 1946-1956 (2013). https://doi.org/10.1016/j. ccr.2012.12.012

130. Chen, Z., Higgins, D., Yu, A., et al.: A review on non-precious metal electrocatalysts for PEM fuel cells. Energy Environ. Sci. 4, 3167-3192 (2011)

131. Chen, J., Takanabe, K., Ohnishi, R., et al.: Nano-sized TiN on carbon black as an efficient electrocatalyst for the oxygen reduction reaction prepared using an mpg- $\mathrm{C}_{3} \mathrm{~N}_{4}$ template. Chem. Commun. 46, 7492-7494 (2010). https://doi.org/10.1039/c0cc02048f

132. Xiao, P., Chen, W., Wang, X.: A review of phosphide-based materials for electrocatalytic hydrogen evolution. Adv. Energy Mater. 5, 1500985 (2015). https://doi.org/10.1002/aenm.20150 0985

133. Sun, M., Liu, H., Qu, J., et al.: Earth-rich transition metal phosphide for energy conversion and storage. Adv. Energy Mater. 6, 1600087 (2016). https://doi.org/10.1002/aenm.201600087

134. Shi, Y., Zhang, B.: Recent advances in transition metal phosphide nanomaterials: synthesis and applications in hydrogen evolution reaction. Chem. Soc. Rev. 45, 1529-1541 (2016). https://doi. org/10.1039/c5cs00434a

135. Xu, Y., Wu, R., Zhang, J., et al.: Anion-exchange synthesis of nanoporous FeP nanosheets as electrocatalysts for hydrogen 
evolution reaction. Chem. Commun. 49, 6656-6658 (2013). https ://doi.org/10.1039/c3cc43107j

136. Popczun, E.J., McKone, J.R., Read, C.G., et al.: Nanostructured nickel phosphide as an electrocatalyst for the hydrogen evolution reaction. J. Am. Chem. Soc. 135, 9267-9270 (2013). https://doi. org/10.1021/ja403440e

137. Popczun, E.J., Read, C.G., Roske, C.W., et al.: Highly active electrocatalysis of the hydrogen evolution reaction by cobalt phosphide nanoparticles. Angew. Chem. Int. Ed. 53, 5427-5430 (2014). https://doi.org/10.1002/anie.201402646

138. Liu, M., Li, J.: Cobalt phosphide hollow polyhedron as efficient bifunctional electrocatalysts for the evolution reaction of hydrogen and oxygen. ACS Appl. Mater. Interfaces 8, 2158-2165 (2016). https://doi.org/10.1021/acsami.5b10727

139. Mendoza-Garcia, A., Su, D., Sun, S.: Sea urchin-like cobalt-iron phosphide as an active catalyst for oxygen evolution reaction. Nanoscale 8, 3244-3247 (2016). https://doi.org/10.1039/c5nr0 $8763 \mathrm{e}$

140. Read, C.G., Callejas, J.F., Holder, C.F., et al.: General strategy for the synthesis of transition metal phosphide films for electrocatalytic hydrogen and oxygen evolution. ACS Appl. Mater. Interfaces 8, 12798-12803 (2016). https://doi.org/10.1021/acsam i. $6 \mathrm{~b} 02352$

141. Lv, Y., Wang, X.: Nonprecious metal phosphides as catalysts for hydrogen evolution, oxygen reduction and evolution reactions. Catal. Sci. Technol. 7, 3676-3691 (2017). https://doi. org/10.1039/c7cy00715a

142. Zhu, Y.P., Liu, Y.P., Ren, T.Z., et al.: Self-supported cobalt phosphide mesoporous nanorod arrays: a flexible and bifunctional electrode for highly active electrocatalytic water reduction and oxidation. Adv. Funct. Mater. 25, 7337-7347 (2015). https://doi. org/10.1002/adfm.201503666

143. Masa, J., Barwe, S., Andronescu, C., et al.: Low overpotential water splitting using cobalt-cobalt phosphide nanoparticles supported on nickel foam. ACS Energy Lett. 1, 1192-1198 (2016). https://doi.org/10.1021/acsenergylett.6b00532

144. Menezes, P.W., Indra, A., Das, C., et al.: Uncovering the nature of active species of nickel phosphide catalysts in high-performance electrochemical overall water splitting. ACS Catal. 7, 103-109 (2016). https://doi.org/10.1021/acscatal.6b02666

145. Wang, X., Li, W., Xiong, D., et al.: Bifunctional nickel phosphide nanocatalysts supported on carbon fiber paper for highly efficient and stable overall water splitting. Adv. Funct. Mater. 26, 4067-4077 (2016). https://doi.org/10.1002/adfm.201505509

146. Yang, H., Zhang, Y., Hu, F., et al.: Urchin-like CoP nanocrystals as hydrogen evolution reaction and oxygen reduction reaction dual-electrocatalyst with superior stability. Nano Lett. 15, 7616-7620 (2015). https://doi.org/10.1021/acs.nanolett.5b03446

147. Doan-Nguyen, V.V., Zhang, S., Trigg, E.B., et al.: Synthesis and $\mathrm{X}$-ray characterization of cobalt phosphide (Co2P) nanorods for the oxygen reduction reaction. ACS Nano 9, 8108-8115 (2015)

148. Chen, K., Huang, X., Wan, C., et al.: Hybrids based on transition metal phosphide $\left(\mathrm{Mn}_{2} \mathrm{P}, \mathrm{Co}_{2} \mathrm{P}, \mathrm{Ni}_{2} \mathrm{P}\right)$ nanoparticles and heteroatom-doped carbon nanotubes for efficient oxygen reduction reaction. RSC Adv. 5, 92893-92898 (2015). https://doi. org/10.1039/c5ra21385a

149. Zhang, R., Zhang, C., Chen, W.: FeP embedded in N, P dualdoped porous carbon nanosheets: an efficient and durable bifunctional catalyst for oxygen reduction and evolution reactions. J. Mater. Chem. A 4, 18723-18729 (2016). https://doi.org/10.1039/ c6ta08363c

150. Qiao, B., Wang, A., Yang, X., et al.: Single-atom catalysis of CO oxidation using $\mathrm{Pt}_{1} / \mathrm{FeO}_{x}$. Nat. Chem. 3, 634-641 (2011)

151. Guo, X., Fang, G., Li, G., et al.: Direct, nonoxidative conversion of methane to ethylene, aromatics, and hydrogen. Science 344, 616-619 (2014)
152. Deng, D., Chen, X., Yu, L., et al.: A single iron site confined in a graphene matrix for the catalytic oxidation of benzene at room temperature. Sci. Adv. 1, e1500462 (2015)

153. Liu, W., Xu, Q., Yan, P., et al.: Fabrication of a single-atom platinum catalyst for the hydrogen evolution reaction: a new protocol by utilization of $\mathrm{H}_{x} \mathrm{MoO}_{3-x}$ with plasmon resonance. ChemCatChem 10, 946-950 (2018)

154. Ball, P.: Single-atom catalysis: a new field that learns from tradition. Natl. Sci, Rev (2018)

155. Kim, J., Roh, C.W., Sahoo, S.K., et al.: Highly durable platinum single-atom alloy catalyst for electrochemical reactions. Adv. Energy Mater. 8, 1701476 (2018)

156. He, F., Li, K., Yin, C., et al.: Single Pd atoms supported by graphitic carbon nitride, a potential oxygen reduction reaction catalyst from theoretical perspective. Carbon 114, 619-627 (2017)

157. Zeng, X., Shui, J., Liu, X., et al.: Single-atom to single-atom grafting of $\mathrm{Pt}_{1}$ onto $\mathrm{Fe}-\mathrm{N}_{4}$ center: $\mathrm{Pt}_{1} @ \mathrm{Fe}-\mathrm{N}-\mathrm{C}$ multifunctional electrocatalyst with significantly enhanced properties. Adv. Energy Mater. 8, 1701345 (2018)

158. Zhang, C., Sha, J., Fei, H., et al.: Single-atomic ruthenium catalytic sites on nitrogen-doped graphene for oxygen reduction reaction in acidic medium. ACS Nano 11, 6930-6941 (2017)

159. Liu, J., Jiao, M., Lu, L., et al.: High performance platinum single atom electrocatalyst for oxygen reduction reaction. Nat. Commun. 8, 15938 (2017)

160. Kim, J., Kim, H.E., Lee, H.: Single-atom catalysts of precious metals for electrochemical reactions. Chemsuschem 11, 104-113 (2018)

161. Zhu, C., Li, H., Fu, S., et al.: Highly efficient nonprecious metal catalysts towards oxygen reduction reaction based on threedimensional porous carbon nanostructures. Chem. Soc. Rev. 45, 517-531 (2016). https://doi.org/10.1039/c5cs00670h

162. Tammeveski, K., Zagal, J.H.: Electrocatalytic oxygen reduction on transition metal macrocyclic complexes for anion exchange membrane fuel cell application. Curr. Opin. Electrochem. 9, 207-213 (2018)

163. Jasinski, R.: A new fuel cell cathode catalyst. Nature 201, 1212 $1213(1964)$

164. Noori, M.T., Verma, N.: Cobalt—iron phthalocyanine supported on carbide-derived carbon as an excellent oxygen reduction reaction catalyst for microbial fuel cells. Electrochim. Acta 298, 70-79 (2019). https://doi.org/10.1016/j.electacta.2018.12.056

165. Sun, C., Li, Z., Yang, J., et al.: Two-dimensional closely packed amide polyphthalocyanine iron absorbed on Vulcan XC-72 as an efficient electrocatalyst for oxygen reduction reaction. Catal. Today (2018). https://doi.org/10.1016/j.cattod.2018.01.029

166. Sun, C., Li, Z., Zhong, X., et al.: Three-dimensional graphenesupported cobalt phthalocyanine as advanced electrocatalysts for oxygen reduction reaction. J. Electrochem. Soc. 165, F24-F31 (2018). https://doi.org/10.1149/2.0521802jes

167. Xu, G., Li, Z., Wang, S., et al.: Planar polyphthalocyanine cobalt absorbed on carbon black as stable electrocatalysts for direct methanol fuel cell. J. Power Sources 195, 4731-4735 (2010). https://doi.org/10.1016/j.jpowsour.2010.01.056

168. Shen, M., Wei, C., Ai, K., et al.: Transition metal-nitrogencarbon nanostructured catalysts for the oxygen reduction reaction: from mechanistic insights to structural optimization. Nano Res. 10, 1449-1470 (2017). https://doi.org/10.1007/s1227 4-016-1400-7

169. Zagal, J.H., Koper, M.T.: Reactivity descriptors for the activity of molecular MN4 catalysts for the oxygen reduction reaction. Angew. Chem. Int. Ed. 55, 14510-14521 (2016). https://doi. org/10.1002/anie.201604311 
170. Xu, H., Cheng, D., Cao, D., et al.: A universal principle for a rational design of single-atom electrocatalysts. Nat. Catal. 1, 339-348 (2018)

171. Wang, C., Li, Z., Wang, L., et al.: Vertical-space-limit synthesis of bifunctional $\mathrm{Fe}, \mathrm{N}$-codoped 2D multilayer graphene electrocatalysts for Zn-Air battery. Energy Technol. (2019). https://doi. org/10.1002/ente.201900123

172. Wang, S., Yan, X., Wu, K.H., et al.: A hierarchical porous $\mathrm{Fe}-\mathrm{N}$ impregnated carbon-graphene hybrid for high-performance oxygen reduction reaction. Carbon 144, 798-804 (2019). https://doi. org/10.1016/j.carbon.2018.12.066

173. Yin, $\mathrm{X}$., Utetiwabo, W., Sun, S., et al.: Incorporation of $\mathrm{CeF}_{3}$ on single-atom dispersed $\mathrm{Fe} / \mathrm{N} / \mathrm{C}$ with oxophilic interface as highly durable electrocatalyst for proton exchange membrane fuel cell. J. Catal. 374, 43-50 (2019). https://doi.org/10.1016/j. jcat.2019.04.028

174. Li, Y., Zhou, W., Wang, H., et al.: An oxygen reduction electrocatalyst based on carbon nanotube-graphene complexes. Nat. Nanotechnol. 7, 394-400 (2012). https://doi.org/10.1038/ nnano.2012.72

175. Yuan, X., Zeng, X., Zhang, H.J., et al.: Improved performance of proton exchange membrane fuel cells with p-toluenesulfonic acid-doped Co-PPy/C as cathode electrocatalyst. J. Am. Chem. Soc. 132, 1754-1755 (2010)

176. Chen, Z., Choi, J.Y., Wang, H., et al.: Highly durable and active non-precious air cathode catalyst for zinc air battery. J. Power Sources 196, 3673-3677 (2011). https://doi.org/10.1016/j. jpowsour.2010.12.047

177. Zhao, Y., Watanabe, K., Hashimoto, K.: Self-supporting oxygen reduction electrocatalysts made from a nitrogen-rich network polymer. J. Am. Chem. Soc. 134, 19528-19531 (2012)

178. Dombrovskis, J.K., Jeong, H.Y., Fossum, K., et al.: Transition metal ion-chelating ordered mesoporous carbons as noble metal-free fuel cell catalysts. Chem. Mater. 25, 856-861 (2013). https://doi.org/10.1021/cm303357p

179. Wang, L., Yin, J., Zhao, L., et al.: Ion-exchanged route synthesis of $\mathrm{Fe}_{2} \mathrm{~N}-\mathrm{N}$-doped graphitic nanocarbons composite as advanced oxygen reduction electrocatalyst. Chem. Commun. 49, 3022-3024 (2013). https://doi.org/10.1039/c3cc40971f

180. Jia, Q., Ramaswamy, N., Hafiz, H., et al.: Experimental observation of redox-induced $\mathrm{Fe}-\mathrm{N}$ switching behavior as a determinant role for oxygen reduction activity. ACS Nano $\mathbf{9}$, 12496-12505 (2015)

181. Li, Y., Liu, D., Gan, J., et al.: Sustainable and atomically dispersed iron electrocatalysts derived from nitrogen-and phosphorus-modified woody biomass for efficient oxygen reduction. Adv. Mater. Interfaces 6, 1801623 (2019)

182. Li, Y., Chen, B., Duan, X., et al.: Atomically dispersed Fe-N$\mathrm{P}-\mathrm{C}$ complex electrocatalysts for superior oxygen reduction. Appl. Catal. B-Environ 249, 306-315 (2019)

183. Dai, L., Xue, Y., Qu, L., et al.: Metal-free catalysts for oxygen reduction reaction. Chem. Rev. 115, 4823-4892 (2015). https ://doi.org/10.1021/cr5003563

184. Su, D.S., Zhang, J., Frank, B., et al.: Metal-free heterogeneous catalysis for sustainable chemistry. Chemsuschem 3, 169-180 (2010)

185. Gara, M., Compton, R.G.: Activity of carbon electrodes towards oxygen reduction in acid: a comparative study. New J. Chem. 35, 2647-2652 (2011)

186. Gong, K., Du, F., Xia, Z., et al.: Nitrogen-doped carbon nanotube arrays with high electrocatalytic activity for oxygen reduction. Science 323, 760-764 (2009)

187. Pels, J., Kapteijn, F., Moulijn, J., et al.: Evolution of nitrogen functionalities in carbonaceous materials during pyrolysis. Carbon 33, 1641-1653 (1995)
188. Guo, D., Shibuya, R., Akiba, C., et al.: Active sites of nitrogendoped carbon materials for oxygen reduction reaction clarified using model catalysts. Science 351, 361-365 (2016)

189. Zhu, Y.P., Liu, Y., Liu, Y.P., et al.: Direct synthesis of phosphorus-doped mesoporous carbon materials for efficient electrocatalytic oxygen reduction. ChemCatChem 7, 2903-2909 (2015)

190. Yang, D.S., Bhattacharjya, D., Inamdar, S., et al.: Phosphorusdoped ordered mesoporous carbons with different lengths as efficient metal-free electrocatalysts for oxygen reduction reaction in alkaline media. J. Am. Chem. Soc. 134, 16127-16130 (2012)

191. Wu, J., Jin, C., Yang, Z., et al.: Synthesis of phosphorus-doped carbon hollow spheres as efficient metal-free electrocatalysts for oxygen reduction. Carbon 82, 562-571 (2015). https://doi. org/10.1016/j.carbon.2014.11.008

192. Zhang, C., Mahmood, N., Yin, H., et al.: Synthesis of phosphorus-doped graphene and its multifunctional applications for oxygen reduction reaction and lithium ion batteries. Adv. Mater. 25, 4932-4937 (2013)

193. Chai, G.L., Qiu, K., Qiao, M., et al.: Active sites engineering leads to exceptional ORR and OER bifunctionality in $\mathrm{P}, \mathrm{N} \mathrm{Co}-$ doped graphene frameworks. Energy Environ. Sci. 10, 11861195 (2017)

194. Bo, X., Guo, L.: Ordered mesoporous boron-doped carbons as metal-free electrocatalysts for the oxygen reduction reaction in alkaline solution. Phys. Chem. Chem. Phys. 15, 2459-2465 (2013)

195. Cheng, Y., Tian, Y., Fan, X., et al.: Boron doped multi-walled carbon nanotubes as catalysts for oxygen reduction reaction and oxygen evolution reaction in alkaline media. Electrochim. Acta 143, 291-296 (2014)

196. Sheng, Z.H., Gao, H.L., Bao, W.J., et al.: Synthesis of boron doped graphene for oxygen reduction reaction in fuel cells. J. Mater. Chem. 22, 390-395 (2012)

197. Yang, L., Jiang, S., Zhao, Y., et al.: Boron-doped carbon nanotubes as metal-free electrocatalysts for the oxygen reduction reaction. Angew. Chem. Int. Ed. 50, 7132-7135 (2011)

198. Ozaki, J.I., Anahara, T., Kimura, N., et al.: Simultaneous doping of boron and nitrogen into a carbon to enhance its oxygen reduction activity in proton exchange membrane fuel cells. Carbon $\mathbf{4 4}$, 3358-3361 (2006)

199. Ozaki, J.I., Kimura, N., Anahara, T., et al.: Preparation and oxygen reduction activity of BN-doped carbons. Carbon 45, 18471853 (2007)

200. Wang, S., Iyyamperumal, E., Roy, A., et al.: Vertically aligned $\mathrm{BCN}$ nanotubes as efficient metal-free electrocatalysts for the oxygen reduction reaction: a synergetic effect by co-doping with boron and nitrogen. Angew. Chem. Int. Ed. 50, 11756-11760 (2011)

201. Wang, S., Zhang, L., Xia, Z., et al.: BCN graphene as efficient metal-free electrocatalyst for the oxygen reduction reaction. Angew. Chem. Int. Ed. 51, 4209-4212 (2012)

202. Liang, J., Jiao, Y., Jaroniec, M., et al.: Sulfur and nitrogen dualdoped mesoporous graphene electrocatalyst for oxygen reduction with synergistically enhanced performance. Angew. Chem. 124, 11664-11668 (2012)

203. Wohlgemuth, S.A., White, R.J., Willinger, M.G., et al.: A onepot hydrothermal synthesis of sulfur and nitrogen doped carbon aerogels with enhanced electrocatalytic activity in the oxygen reduction reaction. Green Chem. 14, 1515-1523 (2012)

204. Yang, S., Mao, X., Cao, Z., et al.: Onion-derived N, S self-doped carbon materials as highly efficient metal-free electrocatalysts for the oxygen reduction reaction. Appl. Surf. Sci. 427, 626-634 (2018). https://doi.org/10.1016/j.apsusc.2017.08.222

205. Su, Y., Zhang, Y., Zhuang, X., et al.: Low-temperature synthesis of nitrogen/sulfur co-doped three-dimensional graphene 
frameworks as efficient metal-free electrocatalyst for oxygen reduction reaction. Carbon 62, 296-301 (2013). https://doi. org/10.1016/j.carbon.2013.05.067

206. Jiang, T., Wang, Y., Wang, K., et al.: A novel sulfur-nitrogen dual doped ordered mesoporous carbon electrocatalyst for efficient oxygen reduction reaction. Appl. Catal. B 189, 1-11 (2016). https ://doi.org/10.1016/j.apcatb.2016.02.009

207. Su, Y., Yao, Z., Zhang, F., et al.: Sulfur-enriched conjugated polymer nanosheet derived sulfur and nitrogen co-doped porous carbon nanosheets as electrocatalysts for oxygen reduction reaction and zinc-air battery. Adv. Funct. Mater. 26, 5893-5902 (2016)

208. Chen, Y., Ji, S., Wang, H., et al.: Synthesis of porous nitrogen and sulfur co-doped carbon beehive in a high-melting-point molten salt medium for improved catalytic activity toward oxygen reduction reaction. Int. J. Hydrog. Energy 43, 5124-5132 (2018). https ://doi.org/10.1016/j.ijhydene.2018.01.095

209. Wang, L., Ambrosi, A., Pumera, M.: "Metal-free" catalytic oxygen reduction reaction on heteroatom-doped graphene is caused by trace metal impurities. Angew. Chem. 125, 14063-14066 (2013)

210. Shi, X., Zhang, J., Huang, T.: The key roles of trace iron for nitrogen, sulfur dual-doped carbon nanospheres as high efficient oxygen reduction catalyst. J. Mater. Sci. 53, 1404-1413 (2018)

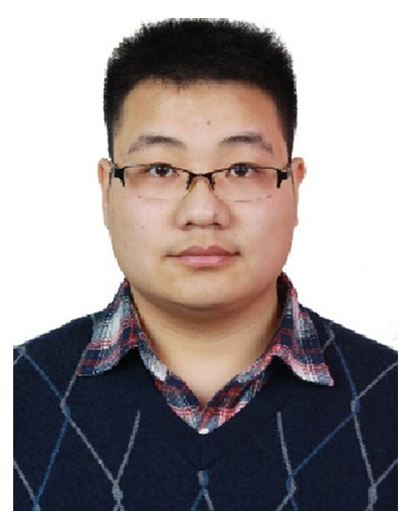

Yahao Li received his B. S. and M.S. degrees in chemistry from Chongqing University in 2011 and 2014, respectively. He obtained his Ph.D. in Chemical Engineering at Norwegian University of Science and Technology (NTNU). Then he worked as a researcher in catalysis group of Department of Chemical Engineering at NTNU. His research interests focus on carbon nanomaterials for energy storage, especially for oxygen reduction reaction.

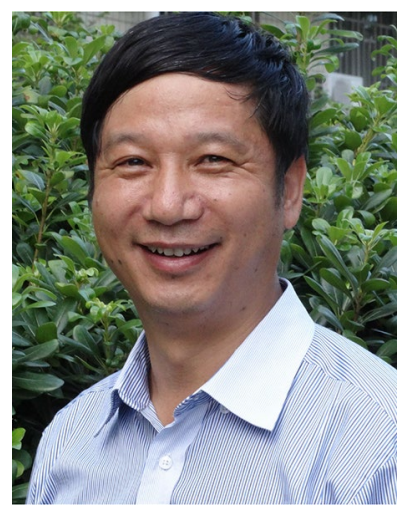

Qinyu Li a Professor of School of Chemistry and Pharmaceutical Sciences at Guangxi Normal University, and the Director of Guangxi Key Laboratory for New Energy Material and Technology. He received his Ph.D. in nonferrous metallurgy from the Central South University in 2003. He is a committee member of Chinese Society of Electrochemistry (CSE) and a board committee member of the International Academy of Electrochemical Energy Science (IAOEES). His researches focus on (a) new energy material-based energy storage systems, including batteries and supercapacitors; and (b) functional materials for energy conservation and environmental protection, particularly for aluminum electrolysis and battery recycling.

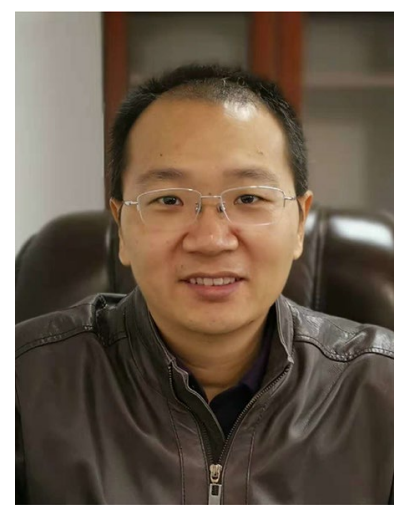

Hongqiang Wang received his Ph.D. in metallurgical physical chemistry from Central South University (China) in 2003. After his Ph.D., He joined the Guangxi Normal University and was promoted to Professor in 2009. Dr. Wang's expertise areas including (1) supercapacitors; (2) lithium ion batteries, lithium-air batteries and battery technology; (3) electroplating technique and aluminum electrolysis. Dr. Wang has successfully completed total 15 projects funded by Chinese Government including National Natural Science Foundation of China (NSFC) and the Key Research and Development Program of Guangxi Province. He has authored over 80 publications in peer-reviewed journals and more than 30 patents in the areas of energy materials, particularly in lithium ion battery, supercapacitors and aluminum electrolysis.

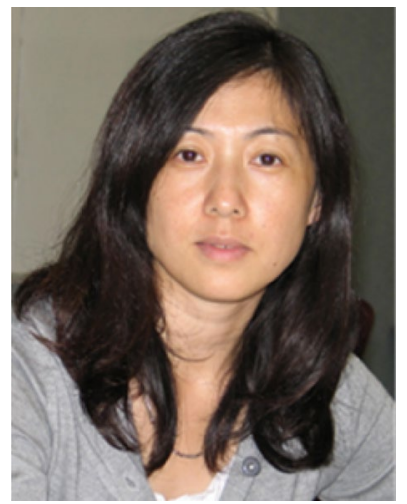

Lei Zhang is a Senior Research Officer at National Research Council Canada (NRC), a Fellow of the Royal Society of Chemistry (FRSC), an adjunct Professor of various Universities. Prof Zhang's expertise areas are electrochemical energy technologies, such as electrocatalysis, fuel cells, supercapacitors, metal-air batteries, and hybrid batteries. She has authored/co-authored more than 170 publications ( 15,000 citations). She was an invited guest lecture and a reviewer for various proposals and refereed journal papers. She is the member of the NSERC Industrial R\&D Fellowships College of Reviewers in Canada, the Editorial Board Member of Electrochemical Energy Reviews (EER), Springer Nature.

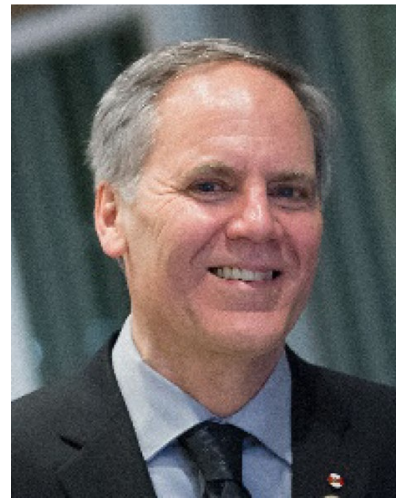

David P. Wilkinson is a Professor and Canada Research Chair in the Department of Chemical and Biological Engineering at the University of British Columbia (UBC). Dr. Wilkinson is a Fellow of Canadian Academy of Engineering (CAE), Fellow of The Academy of Science of The Royal Society of Canada (FRSCCA), Fellow of The Engineering Institute of Canada (EIC). He previously held the positions of Executive Director of the UBC Clean Energy Research Center, Principal Research Officer and Senior Advisor with the National Research Council of Canada Institute for Fuel Cell Innovation, Director and Vice President of Research and Development at Ballard Power Systems, and Group Leader at Moli Energy. His main research interests are in electrochemical and 
photochemical devices, energy conversion and storage materials, and processes to create clean and sustainable energy and water.

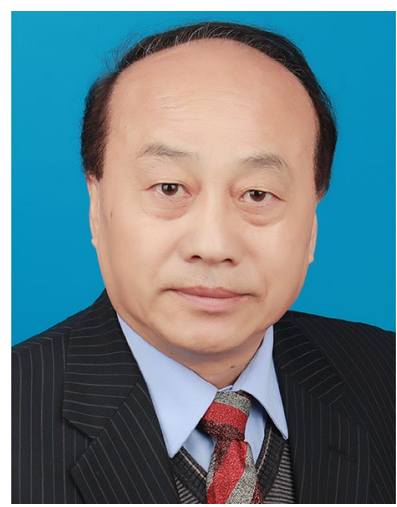

Jiujun Zhang is a Professor in College of Sciences/Institute for Sustainable Energy at Shanghai University, a former Principal Research Officer (Emeritus) at National Research Council of Canada (NRC). Dr. Zhang is a Fellow of Canadian Academy of Engineering (CAE), Fellow of The Academy of Science of The Royal Society of Canada (FRSCCA), Fellow of The Engineering Institute of Canada (EIC), Fellow of International Society of Electrochemistry (ISE), and Fellow of the Royal Society of Chemistry (RSC-UK). Dr. Zhang received his B.S. and M.Sc. in Electrochemistry from Peking University in 1982 and 1985, respectively, and his Ph.D. in Electrochemistry from Wuhan University in 1988. Dr. Zhang serves as Editor-in-Chief of Electrochemical Energy Reviews (Springer Nature) and Associate Editor of Green Energy \& Environment (KeAi), Editor of International Journal of Electrochemistry (Hindawi), and editorial board member for several international journals as well as Editor for book series of Electrochemical Energy Storage and Conversion (CRC). 